\title{
The role of contextual and prosodic factors on consonant lenition and elision. The case of intervocalic [j] in Majorcan Catalan
}

DANIEL RECASENS

AINA ESPINOSA

Abstract

This paper looks for an interpretation of the phonetic factors causing consonant lenition and elision to occur through an analysis of intervocalic [j] in Majorcan, a dialect of Catalan spoken in the Mediterranean island of Majorca. Articulatory and acoustic data for several Majorcan Catalan speakers still producing the palatal glide in all word positions and segmental environments show that the consonant is lower and more variable in intervocalic position than word initially and word finally. Lowering is enhanced by the presence of contextual low and mid low front vowels, mostly so if stressed and placed immediately after the palatal glide. Inspection of $[\mathrm{VjV}]$ formant trajectories suggests that, in spite of undergoing articulatory reduction, $[j]$ is produced with an independent articulatory gesture; moreover, coarticulatory effects between the palatal glide and the following vowel may render the former phonetic segment perceptually indistinguishable from the latter and thus prone to undergo elision. Strongly lenited variants of intervocalic [j] appear to be receding, and conservative speakers show specially low realizations of the palatal glide which may have been widely spread among the speaking population at the time that the intervocalic consonant underwent systematic elision in some areas of Majorca in the past. These findings are in support of the notion that the lenition and subsequent elision of intervocalic consonants are assisted by contextual and prosodic factors.

\section{Introduction}

A goal of the present study is to search for a better understanding of the phonetic mechanisms causing consonant lenition and elision to occur. Elision 
is often associated with maximal articulatory reduction and results from the speakers' failure to achieve the appropriate articulatory target as the consonant is shortened in favorable conditions, e.g., syllable finally and intervocalically in fast speech.

A relevant case of consonant lenition and elision is found in Majorcan Catalan where intervocalic word medial [j] has a specially low realization and has dropped through the entire lexicon in some geographical areas (e.g., ['paə] for ['pajə] palla "straw"). This elision process has operated systematically in intervocalic medial position in the neighbouring island of Minorca. In Majorcan (and Minorcan), the consonant in question is fully realized as [j] in all other word positions, i.e., word initially after a pause or a vowel (['jambə], both in iambe "iambus" and in fa iambes "he/she composes iambuses") and word finally before a pause or a vowel ([rej], both in rei "king" and in rei entristit "sad king"). The goal of this paper is to explore whether a phonetic analysis of Majorcan [j] may throw light into the factors involved in the lenition and elision of the intervocalic allophone of the palatal glide and of intervocalic consonants in general.

Majorcan is a dialect of Catalan spoken by about half million people in the Balearic island of Majorca since the XIII-XIV centuries. Catalan is also spoken by about six milion people in Northeastern Spain around the Barcelona region and in the Valencian provinces along the Mediterranean coast. Insularity accounts for the presence in Majorcan of autochthonous and archaic linguistic characteristics (Bibiloni, 1983, Recasens, 1996): stressed /ə/, in addition to the seven vowel phonemes of the Catalan language /i, e, $\varepsilon, \mathrm{a}, \mathrm{o}$, $\curvearrowright, \mathrm{u} /$; a fairly open realization of $/ \varepsilon, \mathrm{\rho} /$ and a close and front realization of $/ \mathrm{a} /$; a palatal stop allophone of $/ \mathrm{k}, \mathrm{g} /$; word final voiced and voiceless stop clusters with a non-syllabic liquid in the first person of the present tense of verbs ([umpl] umpl "I fill up", [entr] entr "I come in").

\section{Mechanisms of intervocalic consonant lenition and elision}

Articulatory reduction for consonants is implemented through a decrease in duration and gestural magnitude resulting in articulatory undershoot as the consonant is overlapped by the adjacent segments in casual speech (Browman and Goldstein, 1990, 1991). The path from reduction to elision may take place through phonetic realizations of little articulatory and acoustic salience, as for final stops in Southern American English and Black English (e.g., tes(t), roa(d); Wells, 1982 (3): 552-553, 558). Another option, which is of primary concern in this paper, is for consonant reduction to give rise to audible and stable allophones. Indeed, variations in voicing and degree of constriction account for the regular sound changes $[\mathrm{p}, \mathrm{t}, \mathrm{k}]>[\mathrm{b}, \mathrm{d}, \mathrm{g}]$ in early Romance and $[\mathrm{b}, \mathrm{d}, \mathrm{g}]>[\beta, \mathrm{\gamma}, \mathrm{\gamma}]$ in present-day Spanish dialects in VCV and analogous sequences (Navarro Tomás, 1972, Amastae, 1995). 
At least two factors appear to be involved in intervocalic consonant lenition and elision, i.e., the primary articulator of the target consonant $(\boldsymbol{a})$ and the phonetic properties of the contextual segments $(\boldsymbol{b})$.

(a) Articulatory reduction affects certain consonants rather than others. Evidence from the Romance languages shows that voicing and lenition are prone to affect back velars presumably since these consonantal realizations are produced with a widespread and undefined occlusion. Elision, on the other

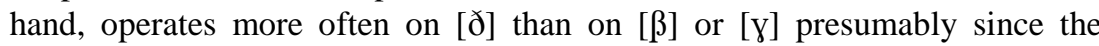
tongue tip articulator is more flexible than the lips and the tongue dorsum (French [vi] vie VITA "life", Lombard [pe] PEDE "foot", popular Tuscan [a'e] avere "to have", Sicilian [pa'ari] pagari "to pay"; Posner, 1997: 220, Rohlfs, 1966: 208, 270, 292-295). Other explanations based on the economy of effort have been proposed in order to account for why apicals delete more frequently than labials and dorsals, i.e., apicals involve greater precision of timing and muscular coordination than the basic, continuously present labial and dorsal movements (Kohler, 1989). Deletion also affects consonants lacking a supraglottal constriction, e.g., the glottal fricative [h] whether derived from [s] in Spanish dialects (Terrell, 1979) or from [k] in Tuscan ([du (h)a'valli] due cavalli "two horses", [a'mi(h)o] amico "friend"; Rohlfs, 1966: 199, 266).

Lenited [j] is resistant to elision presumably due to the high articulatory constraints involved in raising the tongue dorsum towards the hard palate and in agreement with coarticulation data showing that (alveolo)palatals do not adapt easily to the surrounding vowels (Recasens, 1999). In addition to Minorcan Catalan, intervocalic [j] drops in Italian zones, Sardinian $([' J(j) \varepsilon]$ HODIE “today”, ['ma(j)u] MAIU “may"; Contini, 1987: 426, Jones, 1988: 324), and areas of Rhaetoromance (Friulian [ta'a] TALIARE "to cut", Fassan ['foa] FOLIA "leaf”, ['paa] PALEA “straw"; Frau, 1984: 167, Guarnerio, 1918: 392).

(b) Consonant lenition has been characterized as phonetically gradual, contextually determined and lexically regular (Labov, 1994: 540-542, Mowrey and Pagliuca, 1985). Thus, it is natural to believe that the lenition of /d/ has taken place through a progressive decrease in amplitude and duration in the context of segments allowing airflow out of the mouth (i.e., open vowels, liquids). Moreover, lenited allophones have been reported to exhibit more or less variability in constriction degree depending on context and position (see data on Cuban Spanish intervocalic /d/ in López Morales, 1992).

As a general rule, the lenition and elision of dental and alveolar consonants occur most often in (mid) low vowel contexts where a large articulatory distance between the vowel and the consonant may prevent the formation of closure or a narrow constriction from taking place. Thus, [ð] elision is particularly frequent after [a] in the suffixes - $\underline{\text { ada, }}$ - $\underline{\text { ador in Valencian }}$ 
Catalan and -ado in Spanish dialects (Recasens, 1996: 231, Zamora Vicente, 1989: 317). Consonant lenition and elision in open vowel contexts has been attributed to an imperative towards effort minimization assuming that maximum articulatory displacement is associated with maximal velocity and articulatory effort (Kirchner, 2004). The elision of lenited consonants in this context may also be viewed as a case of assimilation through which listeners fail to hear a strongly reduced consonantal realization next to similar phonetic segments.

Dental and alveolar consonants are prone to lenite and drop in posttonic position. Posttonic lenition is documented in Tuscan and Castilian Spanish (Giannelli and Savoia, 1978: 32, Cole, Hualde and Iskarous, 1998, Lavoie, 2001). Posttonic elision has affected [ð] in the Spanish and Catalan suffixes referred to above and in Drôme Provençal ([rwa] ROTA "wheel" as opposed to [na'da] NATARE "to swim"; Bouvier, 1976: 139), as well as other apical consonants such as [n] and [r] in Campidanese Sardinian (['bĩũ] VINU "wine", ['prũã] PRUNA "plum", [kom'mai] comare "godmother"; Contini, 1987: 454, Blasco, 1984: 218). Sociolinguistic studies on Caribean Spanish also reveal a trend for [ð] elision to take place posttonically next to a low vowel (Cedergren, 1979, López Morales, 1992).

Labials and velars may also undergo lenition and elision in the context of open vowels, e.g., [ $\gamma]$ before [a] in Tuscan ([si ' $\beta$ aa] si baca "it rots"; Giannelli and Savoia, 1978: 31) and [ $\beta]$ in the $3^{\text {rd }}$ person ending of the Imperfect tense in Ladin (-['aa] -ABAT; Haiman and Bernincà, 1992: 72). More often, these consonants may lenite and drop next to vocalic segments with which they share the same constriction place, e.g., [g] lenition may occur before a back rounded vowel in Tuscan and the elision of $[\beta, \gamma]$ may take place next to a back labial vowel or glide in several languages and dialects (dialectal Catalan [Ka'o] llavor LABORE "seed", [a'rua] arruga RUGA "wrinckle"; Recasens, 1996: 200, 246).

The scenario for the elision of intervocalic $[\mathrm{j}]$ is not too different from the one just described. Thus, in the Romance languages, intervocalic [j] may be absorbed by (mid) high front vowels whether systematically (e.g., in American Spanish dialects, as in [ku'tfio] cuchillo "knife", [es'trea] estrella "star"; Lipski, 1990, 1994) or in specific lexical items derived from Latin presumably through the stages $[\mathrm{f}]>[\mathrm{j}]>[\varnothing]$ (Catalan ['mestrə] mestre MAGISTRU "teacher", ['rejnə] reina REGINA "queen", [rumi'a] rumiar RUMIGARE "ruminate"). In American Spanish, [j] may not only drop next to a front vowel but also whenever one of the two flanking vowels is [a] (Lipski, 1990) or in segmental combinations involving [a] and/or [o] ([aja], [ajo], [oja], [ojo] in New Méjico; Espinosa, 1930: 198-199); moreover, elision is prone to occur posttonically rather than pretonically when the triggering segment is a (mid) high front vowel and perhaps [a] and [o] as well (Espinosa, 1930, Henríquez Ureña, 1938). 
The sound change data reviewed so far suggest that the elision of lenited labial, palatal and velar consonants may be implemented through two different processes, i.e., absorption in similar phonetic environments and deletion in maximally open contexts. As proposed in the following section, we would like to argue that both processes are different manifestations of a single elision mechanism operating on consonant productions exhibiting different degrees of lenition.

\section{The Majorcan case}

Impressionistic descriptions indicate that intervocalic [j] in Majorcan Catalan has an [e]-like realization which may be more close after high [u] than in other vowel contexts (Bibiloni, 1983). This phonetic characterization is in agreement with the absorption of [j] by adjacent [i] and [e] in areas of Majorca where the glide does not drop systematically, e.g., [fi] for [fij] fill "son", ['veə] for ['vejə] vella "old (fem.)", [pə'e] paller "straw loft", [ku'erə] cullera "spoon".

Spectrographic data for one Majorcan Catalan speaker reported in Mascaró and Rafel (1981) reveal however that intervocalic [j] is not always produced as [e] but exhibits a highly variable realization ranging from [i] $(\mathrm{F} 1=300 \mathrm{~Hz}, \mathrm{~F} 2=2000-2200 \mathrm{~Hz})$ to $[\varepsilon](\mathrm{F} 1=500-550 \mathrm{~Hz}, \mathrm{~F} 2=1400-1800 \mathrm{~Hz})$. These acoustic values suggest that productions of the allophone in question may vary a great deal in degree of dorsopalatal constriction and/or of oral opening (since both articulatory properties are positively correlated with F1). Moreover, the finding that low realizations of the palatal glide may also exhibit a lower $\mathrm{F} 2$ than $[\varepsilon]$ indicates that those variants may be less anterior and more centralized than higher ones (since F2 varies directly with vowel fronting). This scenario is clearly in contrast with that for other Catalan dialects where intervocalic [j] is highly resistant to vocalic effects and exhibits more extreme formant values than [i], i.e., F1 at about $200 \mathrm{~Hz}, \mathrm{~F} 2$ slightly above $2000 \mathrm{~Hz}$, and F3 at about 2500-3000 Hz (Recasens, 1986).

A detailed analysis of vowel coarticulatory effects on [j] in Majorcan Catalan may contribute to our understanding of the articulatory factors causing [j] lowering to occur. According to spectrographic data reported in Mascaró and Rafel (1981), F1 frequency for intervocalic [j] varies as a function of vowel context in the following progression: ['ojə] (pessigoies “tickling") > [u'ja, 'عjə, ə'jo, e'ja] (espuiada "naked", xumeneia "chimney", toveiola "towel", ajoneiat "kneeled down") > [əjə] (trebaiarà "he/she will work") > ['ejə, o'ja] (veia “old (fem.)”, enjoiat "bejewelled”) > ['ujə] (fuia "leaf") $>$ [u'ja, 'əjə] (uiastre "unproductive olive tree", ceies "eyebrows"). This hierarchy of vowel contexts suggests that contextual low or mid low vowels cause maximal lowering in [j].

Based on these acoustic data it is not surprising that the elision of the palatal glide should occur not only in the adjacency of (mid) front vowels but 
of lower vowels as well. In agreement with this possibility, a monograph on the Majorcan dialect of Sóller (Mas, 1960) acknowledges that intervocalic [j] is most prone to drop before stressed [a] in the sequence [ə'ja] where the glide may alternate with $[\varnothing]$ in words such as [bəbə'janə] babaiana "butterfly" and [bəðə'ja] badaiar "to yawn" (also [ə'jo] may become [ə'o] in [kəvə'jo] cavaió "roof ridge" and other lexical items). Other sequences keep a fading but nevertheless audible glide, e.g., ['əjə] oveia "sheep", ['ejə] reia "ploughshare", ['ujə] fuia "leaf", [ə'jə] cabeiera "head of hair".

In the light of the descriptive and experimental evidence reviewed so far, the present study will try to elucidate whether intervocalic [j] in Majorcan Catalan exhibits minimally lenited [e]-like realizations, maximally lenited $[\varepsilon]$-like realizations, or else variable realizations ranging from an [e]-like glide next to (mid) high front vowels to an $[\varepsilon]$-like glide next to mid low front and low vowels. Elision could be accounted through gestural overlap in all three scenarios, i.e., gestural overlap would cause elision to occur next to (mid) high front vowels if $[j]$ is realized as $[e]$, next to (mid) low front vowels if $[j]$ is realized as $[\varepsilon]$, or in a wide range of vowel contexts proceeding from [i, e] to $[\varepsilon, a]$ if the palatal glide turns out to be highly variable along the vowel height dimension. It may also be that [j] elision next to (mid) high front vowels in sequences such as [iji] and [eje] does not proceed through lenition but results from the perceptual confusion between two highly similar non-lenited phonetic segments in succession. It appears however that, while being at work next to [i], this confusion process would be less prone to apply next to [e] where some degree of undershoot in the palatal glide may be required for elision to occur.

Other phonetic aspects will be looked into in the present study. In order to determine whether lenition and elision are favored by centralization, we will check if intervocalic [j] may be realized through [0]-like phonetic variants and whether these variants are associated with higher and/or lower productions of the palatal glide. We will also investigate the extent to which [j] lowering depends on stress position and on the position of the vowel triggering lenition in the $[\mathrm{VjV}]$ sequence. $[\mathrm{VjV}]$ formant trajectories will also be analyzed in order to ascertain whether the glide is implemented through an independent acoustic target and thus, through a specific articulatory gesture, even when exhibiting lenited realizations. These formant trajectories will also allow to determine whether prominent anticipatory and/or carryover effects exerted by [j] cause the consonant to be perceptually indistinguishable from the immediately preceding and/or following vowels which would account for glide elision. In particular, coarticulation theory predicts that prominent carryover effects in tongue dorsum raising and fronting associated with [j] ought to result in a higher F2 during the following vowel, mostly so if the vowel in question is targetless schwa or else [a] which is specially front in Majorcan Catalan (Recasens, 1999). 


\section{Method}

The sequences listed in Table I were read seven times as naturally as possible by five male speakers of Majorcan Catalan (AR, BM, MJ, ND, CA). All five speakers are 25-45 years of age, were born and are presently living in Majorca, and use Majorcan Catalan almost exclusively in their everyday life. In sentences 1-12 of the table, the palatal glide may occur word initially (1-3), word finally (4-6) and intervocalically (7-12). These positions were chosen since Majorcan [j] is expected to be realized as a constricted approximant word initially and word finally, and to undergo lenition in intervocalic word medial position. Word initial and word final [j] occurred utterance initially after a pause and utterance finally before a pause, respectively. In order to allow for vowel coarticulation and intervocalic lenition, the consonant was accompanied by the vowels $[\mathrm{e}, \mathrm{a}, \mathrm{u}]$ in word initial and word final position, and showed up in the vocalic contexts ['aə, 'əə, 'uə, əə, ə'a, u'a] in intervocalic position. These six VCV sequences allowed testing the extent to which [j] was affected by contextual low, high back and central vowels ([a, u, ə]), as well as by stress position and the quality of the vowels preceding and following the glide (e.g., in the sequence pairs ['ajə] vs. [ə'ja] and ['ujə] vs. [u'ja]). Sequences with neighbouring [i] or [e] have been excluded from analysis based on the belief that [j] would now be hard to be identified perceptually and isolated from the contextual vowels in the segmentation procedure. In any case, the fact that the word roveiat in sequence 11 of the table was pronounced [rove'jat] rather than [rovə'jat] by speaker ND allowed carrying out a phonetic analysis of [j] next to contextual [e].

Acoustic and electropalatographic (EPG) data were recorded simultaneously. EPG recordings are carried out in laboratory settings and provide linguopalatal contact patterns over time by means of artificial palates placed in the speaker's mouth. Artificial palates interfere less with the subject's speech than other devices used for recording articulatory movement and aerodynamic data. The analysis of EPG contact configurations may be used in order to formulate plausible hypotheses about the articulatory mechanisms involved in speech production and phonemic variation and change. The need for collecting articulatory data is also justified by the existence of a non-linear relationship between articulation and acoustics, namely, by the fact that variations along certain articulatory dimensions (e.g., changes in place of articulation over the palatal zone) may have negligeable acoustic consequences. In the present experiment, contact configurations were gathered with the Reading EPG-3 system every $10 \mathrm{~ms}$ using artificial palates equipped with 62 electrodes (Hardcastle, Jones, Knight, Trudgeon and Calder 1989), and acoustic data were digitized at $10 \mathrm{kHz}$ and filtered at $4.8 \mathrm{kHz}$.

The segmentation of [j] was performed according to the following criteria. Initial [j] was considered to start at the onset of voiced formant structure, and end at the onset of the F1 transition towards the following vowel which usually coincided with the offset of a dorsopalatal constriction maximum on the EPG record. On the other hand, final [j] was taken to extend from the 
offset of the F1 transition for the preceding vowel (which coincided with the onset of a dorsopalatal constriction maximum) until the offset of voiced formant structure. Articulatory and acoustic data for [j] were measured at the midpoint of the consonantal period.

TABLE I. List of sequences represented in dialectal Catalan orthography.

\section{Word initial}

1. [je]

2. [ja]

3. [ju]

\section{Word final}

4. [ej]

5. [aj]

6. [uj]

\section{Intervocalic}

7. ['ajə]

8. ['วjə]

9. ['uja]

10. [әјə]

11. [ə'ja]

12. [u'ja] hiena africana

iambe assonant

iuca tropical

és un mal rei

no vindrà mai

això no ho vull
"African hyena"
"assonant iamb"
"tropical yucca"

"he is a bad king"

"he/she will not ever come"

"I do not want it"

Segmentation proved to be specially hard in the case of $[\mathrm{VjV}]$ sequences since intervocalic $[\mathrm{j}]$ was realized through a specially wide dorsopalatal constriction and the VC and $\mathrm{CV}$ formant transitions proceeded gradually in this case. For this reason, data for intervocalic [j] were not computed at consonant midpoint but at the temporal frame showing a maximal F2 frequency within the overall VCV period. As revealed by the formant trajectories for speakers BM and MJ in Figure 6, this criterion was clearly justified whenever F2 exhibited a convex shape, namely, a prominent VC rising movement followed by a long CV lowering movement. This F2 shape was less obvious for speakers $\mathrm{AR}, \mathrm{ND}$ ad CA since their CV trajectories were short and underwent little frequency lowering; in particular, F2 trajectories for speaker CA showed a long VC rising movement followed by a short and flat $\mathrm{CV}$ portion. For all speakers, if the F2 frequency maximum lasted for several frames, the consonant was measured at the first frame of a F2 plateau which usually coincided with an F1 frequency minimum. 
FIGURE 1. EPG contact configurations for [j] in initial position (top row), final position (second row) and intervocalic position (two bottom rows) for the Majorcan speaker BM. Contact patterns correspond to the vowel contexts [e, a, u] (initial, final), and ['a९, '९९, 'u९, ९९, ९'a, u'a] (intervocalic). Intervocalic stressed vowels appear underlined. See text for details about the graphic representation of the EPG contact patterns.

Initial
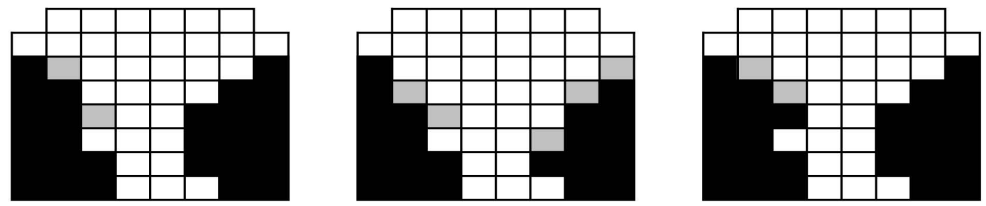

Final

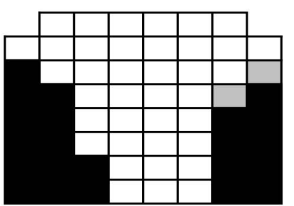

e

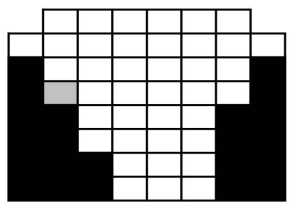

a

Intervocalic

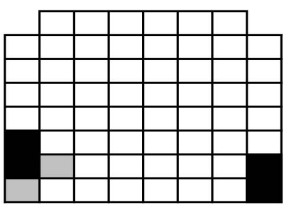

â9

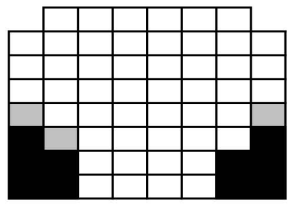

९९

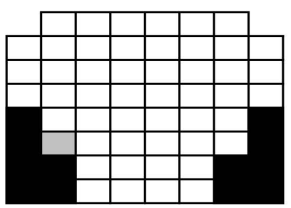

999

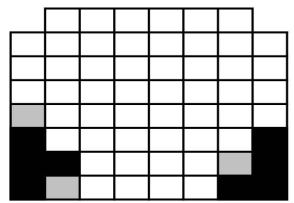

9aㅡ

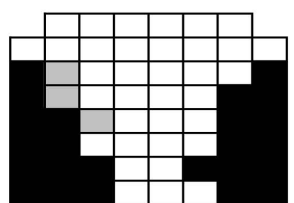

$\mathrm{u}$

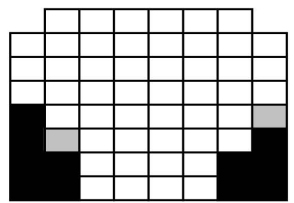

노

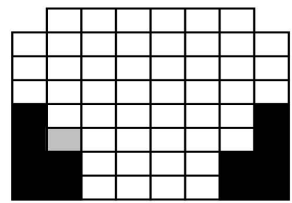

ua 
EPG data were analyzed from contact configurations such as those displayed in Figure 1. As shown in the figure, electrodes placed on the surface of the artificial palates are arranged in eight rows and in four columns on the left and right half sides. The frontmost row 1 (just behind the upper teeth) is displayed at the top of the graphs and the backmost row 8 (just in front of the soft palate) at the bottom; columns 1 and 4 are the most external and innermost columns of electrodes, respectively. The artificial palate surface has been subdivided into four articulatory zones for data interpretation, i.e., front alveolar (rows 1, 2), postalveolar (rows 3, 4), prepalatal (rows 5, 6), mediopalatal (7) and postpalatal (8). Electrodes appear in black, grey or white depending on frequency of activation across repetitions, i.e., 80-100\% (black), 40-80\% (grey) and less than $40 \%$ (white).

Several articulatory parameters were measured, i.e., Qp (quotient of overall electrode activation at the palatal zone), CA (contact anteriority over the entire palate) and $\mathrm{CCp}$ (contact centrality at the palatal zone). Computation of the $\mathrm{Qp}$ and CCp values was restricted to the palatal zone, i.e., to the four back rows 5 through 8 , since central contact for [j] did not extend into the alveolar region; on the other hand, contact anteriority (CA) was measured over all eight rows since maximal anteriority for [j] occurred invariably at the sides of the front four rows. The index Qp was obtained averaging all contacted electrodes at the palatal zone by the total amount of 32 electrodes at that zone and rescaling the resulting values so that a range between 0 to 1 was obtained. The indices CA and CCp were applied using the following formula (Fontdevila, Pallarès and Recasens, 1994):

$$
\begin{aligned}
& \mathrm{CA}=\left[\operatorname { l o g } \left[\left[1\left(\mathrm{R}_{8} / 8\right)+9\left(\mathrm{R}_{7} / 8\right)+81\left(\mathrm{R}_{6} / 8\right)+729\left(\mathrm{R}_{5} / 8\right)+6561\left(\mathrm{R}_{4} / 8\right)+\right.\right.\right. \\
& \left.\left.\left.59049\left(\mathrm{R}_{3} / 8\right)\right]+531441\left(\mathrm{R}_{2} / 8\right)+3587227\left(\mathrm{R}_{1} / 6\right)+1\right]\right] / \\
& \quad[\log (4185098+1)] . \\
& \mathrm{CCp}=\left[\log \left[\left[1\left(\mathrm{C}_{1} / 8\right)+9\left(\mathrm{C}_{2} / 8\right)+81\left(\mathrm{C}_{3} / 8\right)+729\left(\mathrm{C}_{4} / 8\right)\right]\right] /[\log (820+1)] .\right.
\end{aligned}
$$

In the ratios within parentheses, the number of contacted electrodes on a given row (i.e., R8, R7, etc. for CA) and on a given column (i.e., C1, C2, etc. for $\mathrm{CCp}$ ) is divided by the total number of electrodes on that row or column. In the CCp index formula, the denominator is always 8 since this is the number of electrodes located on all symmetrical columns at both sides of the palate. Each ratio is multiplied by a coefficient number. These coefficients are chosen so that the activation of all electrodes at a specific row or column yields a lower index value than the activation of a single electrode at more anterior rows (CA) or at more central columns (CCp).

$\mathrm{F} 1, \mathrm{~F} 2$ and F3 frequencies were measured manually on spectrographic displays using the same temporal resolution as the EPG data with the Kay CSL (Computerized Speech Lab) acoustic analysis system. The third formant could not be measured successfully for initial and final [j] in the case of speakers BM, ND and CA due to its low intensity level. Formant frequency 
trajectories for the entire $[\mathrm{VjV}]$ sequences were traced using LPC (linear prediction coding).

Specific articulatory-acoustic relationships are expected to hold for $[\mathrm{j}]$ (Fant 1960, Bladon 1979, Stevens, 1998): F2 should be positively related to tongue dorsum raising and fronting and to dorsopalatal contact size (and thus, positively related to $\mathrm{Qp}$ and $\mathrm{CCp}$ ), and inversely related to the length of the cavity behind the primary constriction and to back constriction narrowing; F1 ought to be positively related to degree of oral opening, to the cross-sectional area of the lateral constriction and to tongue dorsum lowering (and thus, inversely related to $\mathrm{Qp}$ and $\mathrm{CCp}$ ); F3 should be front-cavity dependent (and thus, positively related to $\mathrm{CA}$ ). Moreover, formant values for [j] are also expected to decrease with an increase in lip rounding in the context of rounded vs. unrounded vowels. A reason for analyzing F3 data was because both second and third formants, which happen to lie close to each other for [j], have been shown to contribute to the perceptual identification of the palatal glide.

The three ANOVAs $(\mathrm{p}<0.05)$ described below were performed on the Qp, CA, CCp, F1 and F2 data in order to elicit the effect of position and vowel context. Bonferroni multiple comparisons tests were applied to significant main effects and interactions.

(a) One-way ANOVAs (ANOVA1) tested the effect of 'position' (initial, intervocalic, final) on the overall data set. Data values were 360 (352 because a few missing values), i.e., 7 repetitions of 3 initial and 3 final sequences by 5 speakers +5 repetitions of 6 intervocalic sequences by 5 speakers.

(b) ANOVAs with repeated measures (ANOVA2) tested the effect of the within-subject factors 'position' (initial, final) and 'vowel' ([e, a, u]); 'speaker' was the between-subject factor. Data values were 204, i.e., 7 repetitions of 6 sequences by 5 speakers, except for speaker ND for which only 6 tokens were available.

(c) ANOVAs with repeated measures (ANOVA3) were run on the data for the intervocalic condition with 'vowel context' as the within-subject factor (['аə, 'əə, 'uə, әә, ə'a, u'a]) and 'speaker' as the between-subject factor. Data values were 150, i.e., 5 tokens of 6 sequences by 5 speakers.

The degree of contextual variability for intervocalic [j] was evaluated for articulatory and acoustic parameters associated with tongue dorsum height and fronting (Qp, F1, F2). Contextual variability was expressed by standard deviations over the mean Qp, F1 and F2 values for the six $[\mathrm{VjV}]$ sequences across speakers. Token-to-token variability across repetitions of each $[\mathrm{VjV}]$ sequence was also calculated for each subject. Qp-F1 and Qp-F2 correlations were performed in order to find out the extent to which F1 and F2 variations conformed to variations in dorsopalatal contact. Articulatory-acoustic correlations were run on mean values across repetitions of each sequence 
within each position (15 values for the initial and final condition, 30 values for the intervocalic condition) and across positions (60 data values). These correlations were performed not only across speakers but for each speaker as well. F1-F2 correlations were also carried out in order to determine the extent to which low realizations of [j] were specially centralized.

In order to ascertain whether speakers intended to produce an independent articulatory gesture for $[\mathrm{j}]$ in intervocalic position, $\mathrm{F} 1$ and $\mathrm{F} 2$ trajectories for all six $[\mathrm{VjV}]$ sequences 7-12 in Table I were traced frame-by-frame. Trajectory averages were computed for each sequence lining up LPC trajectories for all individual repetitions at the F2 frequency maximum. Speakers were considered to perform an independent dorsal gesture for [j] if formant trajectories moved towards the prototypical frequency values for this consonant, i.e., $200 \mathrm{~Hz}(\mathrm{~F} 1)$, $2000 \mathrm{~Hz}(\mathrm{~F} 2)$ and $3000 \mathrm{~Hz}(\mathrm{~F} 3)$. Inspection of these [VjV] trajectories also provided information about whether consonant-dependent carryover coarticulatory effects caused the following vowel (mostly V2=[ə] or V2=[a]) to exhibit similar formant frequencies to those for [j].

Results

\section{Position}

ANOVA1 tests yielded a significant effect of position for all contact indices, i.e., dorsopalatal contact (Qp; $\mathrm{F}(2,349)=750.08$, $\mathrm{p}<0.001)$, overall contact fronting $(\mathrm{CA} ; \mathrm{F}(2,349)=1333.26, \mathrm{p}<0.001)$ and dorsopalatal contact centrality $(\mathrm{CCp} ; \mathrm{F}(2,349)=695.89, \mathrm{p}<0.001)$. As shown in Figure 2 (top graph), all three contact index values varied significantly in the progression initial $>$ final $>$ intervocalic. Moreover, while differences between the two former positions are small, those between intervocalic $[\mathrm{j}]$ and initial and final $[\mathrm{j}]$ are very large. Thus, for example, mean Qp values reach 0.68 for initial [j], 0.62 for final [j] and 0.25 for intervocalic [j]. Palatographic contact configurations in Figure 1 show indeed a less constricted and more posterior realization of [j] in all intervocalic sequences than in initial and final position, and analogous but much less obvious contact differences between initial [j] and final [j].

Statistical results for the formant data were in agreement with those for the contact data. F1 decreased significantly in the progression intervocalic $>$ final $>$ initial $(\mathrm{F}(2,350)=533.81, \mathrm{p}<0.001)$, and $\mathrm{F} 2$ was higher initially and finally than intervocalically $(\mathrm{F}(2,350)=269.85, \mathrm{p}<0.001)$. Formant data in the bottom graph of Figure 2 also indicate the presence of a higher F1 and a lower F2 for intervocalic [j] $(519 \mathrm{~Hz}, 1869 \mathrm{~Hz})$ than for [j] in the other two positions (initial $=294 \mathrm{~Hz}, 2296 \mathrm{~Hz}$; final $=325 \mathrm{~Hz}, 2274 \mathrm{~Hz}$ ). Formant frequency differences between the initial and final allophones of the palatal glide are small and significant for F1 but not for F2. 
FIGURE 2. Contact index values (Qp, CA, CCp; top) and formant frequency values (F1, F2, F3; bottom) for [j] as a function of word position across speakers.
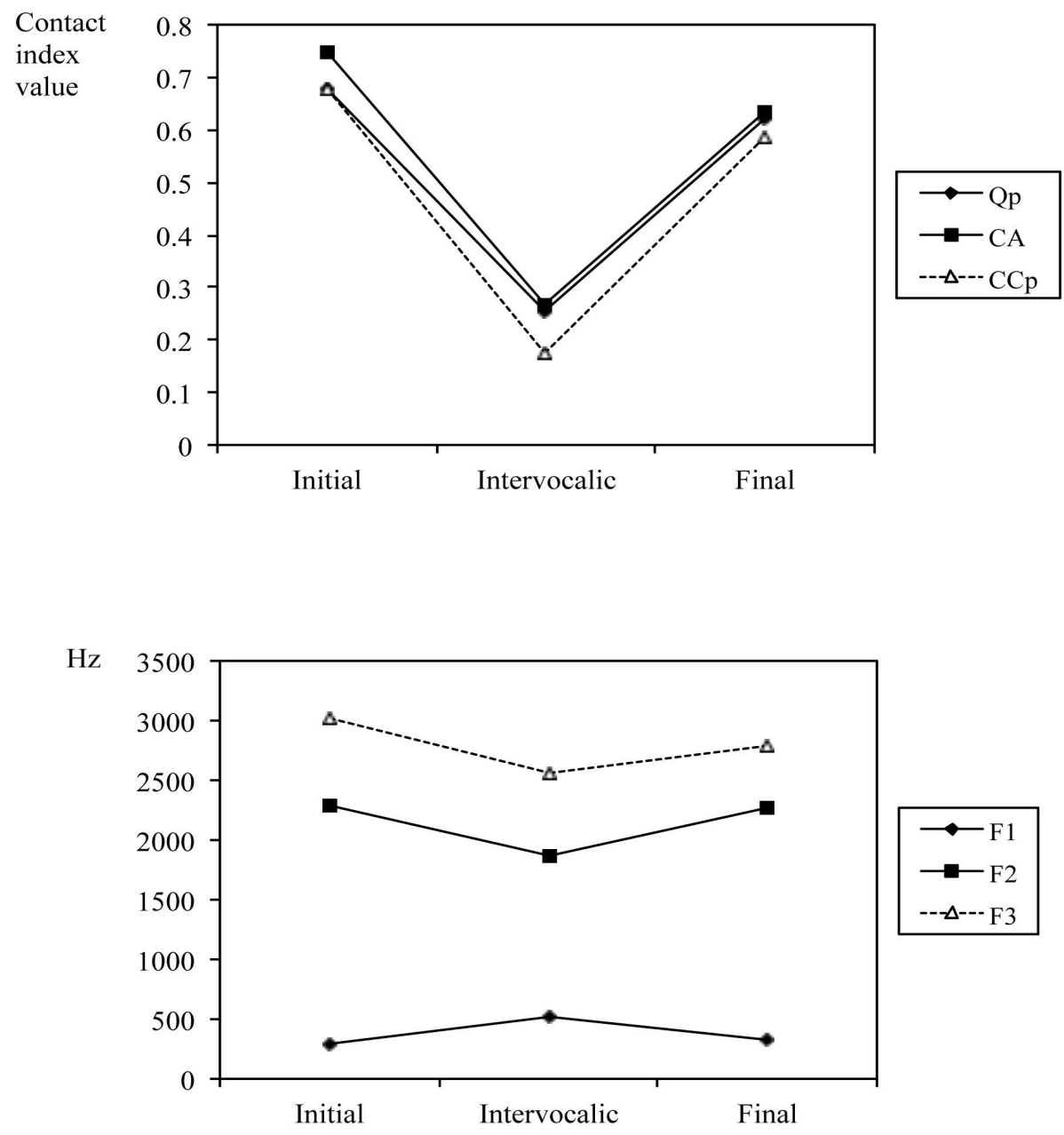
TABLE II. Qp, CCp, CA, F1, F2 and F3 values for initial, final and intervocalic [j] for each speaker and across speakers. Means across repetitions are given in boldface, and standard deviations appear in italics. Stressed vowels in the $[\mathrm{VjV}]$ sequences appear underlined. F3 values may be absent or unaccompanied by standard deviations if corresponding to a single repetition.

\begin{tabular}{|c|c|c|c|c|c|c|c|c|c|c|c|c|c|c|}
\hline & & & \multicolumn{2}{|c|}{$\mathrm{Qp}$} & \multicolumn{2}{|c|}{$\mathrm{CCp}$} & \multicolumn{2}{|c|}{$\mathrm{CA}$} & \multicolumn{2}{|c|}{ F1 } & \multicolumn{2}{|c|}{ F2 } & \multicolumn{2}{|c|}{ F3 } \\
\hline \multirow[t]{12}{*}{$\mathrm{AR}$} & \multirow{2}{*}{ Initial } & $\mathrm{e}$ & 0.54 & 0.06 & 0.62 & 0.12 & 0.79 & 0.02 & 274 & 22.25 & 2237 & 93.40 & & \\
\hline & & $\mathrm{a}$ & 0.52 & 0.05 & 0.52 & 0.04 & 0.75 & 0.07 & 337 & 42.31 & 2143 & 115.14 & & \\
\hline & & $\mathrm{u}$ & 0.51 & 0.04 & 0.57 & 0.08 & 0.80 & 0.02 & 283 & 29.28 & 2117 & 72.51 & 2608 & 67.23 \\
\hline & Final & $\mathrm{e}$ & 0.58 & 0.02 & 0.55 & 0.03 & 0.60 & 0.08 & 306 & 15.12 & 2213 & 66.53 & 2757 & 118.56 \\
\hline & & $\mathrm{a}$ & 0.62 & 0.06 & 0.59 & 0.03 & 0.62 & 0.02 & 311 & 10.69 & 2197 & 117.43 & 2657 & 105.47 \\
\hline & & $\mathrm{u}$ & 0.50 & 0.09 & 0.46 & 0.13 & 0.66 & 0.06 & 309 & 15.74 & 2074 & 147.74 & 2740 & 28.28 \\
\hline & Interv & a99 & 0.21 & 0.03 & 0.09 & 0.01 & 0.29 & 0.08 & 521 & 50.3 & 1896 & 25.74 & 2511 & 46.36 \\
\hline & & $\underline{99}$ & 0.24 & 0.01 & 0.10 & 0.00 & 0.34 & 0.02 & 427 & 7.78 & 1804 & 53.44 & 2455 & 26.05 \\
\hline & & u9 & 0.23 & 0.04 & 0.11 & 0.04 & 0.29 & 0.07 & 437 & 6.38 & 1628 & 52.65 & 2320 & 54.58 \\
\hline & & 99 & 0.24 & 0.01 & 0.10 & 0.00 & 0.35 & 0.00 & 456 & 13.92 & 1753 & 41.54 & 2485 & 69.44 \\
\hline & & $9 \underline{\mathrm{a}}$ & 0.24 & 0.01 & 0.10 & 0.00 & 0.34 & 0.02 & 540 & 16.12 & 1753 & 40.36 & 2525 & 30.42 \\
\hline & & ua & 0.24 & 0.07 & 0.14 & 0.07 & 0.26 & 0.08 & 557 & 50.30 & 1602 & 34.44 & 2448 & 64.48 \\
\hline BM & Initial & e & 0.69 & 0.04 & 0.66 & 0.07 & 0.66 & 0.01 & 246 & 9.76 & 2529 & 55.21 & & \\
\hline & & $\mathrm{a}$ & 0.63 & 0.06 & 0.60 & 0.08 & 0.62 & 0.02 & 291 & 42.98 & 2511 & 90.08 & & \\
\hline & & $\mathrm{u}$ & 0.70 & 0.02 & 0.66 & 0.05 & 0.67 & 0.04 & 273 & 48.44 & 2423 & 23.38 & & \\
\hline & Final & e & 0.58 & 0.04 & 0.55 & 0.09 & 0.65 & 0.05 & 320 & 25.82 & 2566 & 76.35 & & \\
\hline & & $\mathrm{a}$ & 0.57 & 0.02 & 0.52 & 0.03 & 0.64 & 0.01 & 363 & 43.86 & 2500 & 51.64 & & \\
\hline & & $\mathrm{u}$ & 0.61 & 0.03 & 0.57 & 0.03 & 0.67 & 0.05 & 349 & 50.14 & 2551 & 76.47 & & \\
\hline & Interv & à 9 & 0.17 & 0.04 & 0.12 & 0.06 & 0.17 & 0.00 & 511 & 45.12 & 2140 & 69.21 & 2873 & 202.41 \\
\hline & & $\underline{99}$ & 0.39 & 0.03 & 0.29 & 0.02 & 0.37 & 0.05 & 403 & 38.26 & 2239 & 34.63 & 2617 & 135.59 \\
\hline & & 노 & 0.38 & 0.05 & 0.30 & 0.02 & 0.32 & 0.06 & 353 & 30.98 & 2086 & 145.86 & 2522 & 52.41 \\
\hline & & 99 & 0.37 & 0.05 & 0.29 & 0.02 & 0.30 & 0.08 & 469 & 23.50 & 2185 & 70.23 & 2578 & 109.20 \\
\hline & & $9 \underline{\mathrm{a}}$ & 0.30 & 0.06 & 0.24 & 0.04 & 0.26 & 0.07 & 564 & 64.37 & 2149 & 122.92 & 2677 & 237.84 \\
\hline & & ua & 0.39 & 0.03 & 0.29 & 0.01 & 0.34 & 0.02 & 479 & 63.08 & 2205 & 80.77 & 2502 & 104.53 \\
\hline MJ & Initial & $\mathrm{e}$ & 0.79 & 0.05 & 0.81 & 0.08 & 0.80 & 0.05 & 331 & 19.52 & 2311 & 38.05 & 3190 & 151.00 \\
\hline & & $\mathrm{a}$ & 0.79 & 0.03 & 0.85 & 0.05 & 0.78 & 0.03 & 337 & 21.38 & 2257 & 31.47 & 3191 & 64.14 \\
\hline & & $\mathrm{u}$ & 0.87 & 0.05 & 0.90 & 0.05 & 0.85 & 0.05 & 314 & 42.76 & 2326 & 42.76 & 2760 & 86.41 \\
\hline & Final & $\mathrm{e}$ & 0.73 & 0.07 & 0.79 & 0.09 & 0.66 & 0.10 & 331 & 48.80 & 2283 & 24.30 & 2863 & 116.29 \\
\hline & & $\mathrm{a}$ & 0.64 & 0.05 & 0.60 & 0.04 & 0.65 & 0.07 & 351 & 30.24 & 2243 & 63.70 & 3031 & 102.54 \\
\hline & & $\mathrm{u}$ & 0.71 & 0.05 & 0.69 & 0.08 & 0.71 & 0.06 & 303 & 29.28 & 2320 & 50.33 & 2909 & 97.20 \\
\hline & Interv & $\underline{\text { a }} 9$ & 0.20 & 0.04 & 0.13 & 0.06 & 0.19 & 0.02 & 565 & 55.92 & 1895 & 27.01 & 2649 & 118.89 \\
\hline & & $\underline{9} 9$ & 0.34 & 0.03 & 0.26 & 0.03 & 0.32 & 0.02 & 487 & 14.04 & 1915 & 54.81 & 2761 & 78.16 \\
\hline & & $\underline{\mathrm{u}} 9$ & 0.28 & 0.07 & 0.22 & 0.09 & 0.26 & 0.07 & 463 & 35.12 & 1939 & 166.46 & 2547 & 59.61 \\
\hline & & 99 & 0.27 & 0.07 & 0.18 & 0.09 & 0.31 & 0.00 & 554 & 23.10 & 1931 & 88.55 & 2782 & 51.86 \\
\hline & & $9 \underline{a}$ & 0.19 & 0.03 & 0.11 & 0.04 & 0.28 & 0.06 & 630 & 18.23 & 1813 & 29.87 & 2701 & 149.61 \\
\hline & & ua & 0.28 & 0.05 & 0.25 & 0.03 & 0.23 & 0.07 & 562 & 23.56 & 1835 & 43.90 & 2500 & 64.33 \\
\hline
\end{tabular}




\begin{tabular}{|c|c|c|c|c|c|c|c|c|c|c|c|c|c|c|}
\hline & & & \multicolumn{2}{|c|}{$\mathrm{Qp}$} & \multicolumn{2}{|c|}{$\mathrm{CCp}$} & \multicolumn{2}{|c|}{$\mathrm{CA}$} & \multicolumn{2}{|c|}{ F1 } & \multicolumn{2}{|c|}{ F2 } & \multicolumn{2}{|c|}{ F3 } \\
\hline \multirow[t]{12}{*}{ ND } & Initial & $\mathrm{e}$ & 0.55 & 0.08 & 0.46 & 0.13 & 0.77 & 0.05 & 297 & 34.45 & 2360 & 92.09 & & \\
\hline & & $\mathrm{a}$ & 0.63 & 0.09 & 0.56 & 0.12 & 0.75 & 0.08 & 313 & 27.33 & 2327 & 45.02 & & \\
\hline & & $\mathrm{u}$ & 0.67 & 0.05 & 0.64 & 0.07 & 0.85 & 0.05 & 257 & 19.66 & 2340 & 70.43 & & \\
\hline & Final & e & 0.55 & 0.05 & 0.46 & 0.09 & 0.68 & 0.05 & 337 & 8.16 & 2210 & 51.77 & & \\
\hline & & $\mathrm{a}$ & 0.55 & 0.04 & 0.47 & 0.09 & 0.66 & 0.01 & 332 & 22.80 & 2264 & 86.49 & & \\
\hline & & $\mathrm{u}$ & 0.56 & 0.04 & 0.50 & 0.08 & 0.62 & 0.02 & 313 & 37.24 & 2160 & 63.25 & 2620 & 53.67 \\
\hline & Interv & $\underline{a} 9$ & 0.14 & 0.07 & 0.07 & 0.03 & 0.22 & 0.08 & 541 & 21.27 & 1839 & 73.45 & 2636 & 22.87 \\
\hline & & $\underline{99}$ & 0.23 & 0.01 & 0.11 & 0.03 & 0.31 & 0.00 & 485 & 18.16 & 1806 & 25.61 & 2645 & 36.14 \\
\hline & & u9 & 0.20 & 0.05 & 0.10 & 0.04 & 0.25 & 0.07 & 484 & 6.66 & 1749 & 73.72 & 2671 & 74.39 \\
\hline & & 99 & 0.16 & 0.05 & 0.10 & 0.06 & 0.20 & 0.06 & 480 & 24.35 & 1807 & 41.10 & 2673 & 85.85 \\
\hline & & э므 & 0.28 & 0.05 & 0.18 & 0.06 & 0.33 & 0.02 & 524 & 13.40 & 1807 & 31.68 & 2631 & 25.05 \\
\hline & & ua & 0.18 & 0.06 & 0.10 & 0.06 & 0.20 & 0.06 & 598 & 31.84 & 1630 & 53.73 & 2414 & 157.28 \\
\hline $\mathrm{CA}$ & Initial & $\mathrm{e}$ & 0.71 & 0.06 & 0.69 & 0.10 & 0.66 & 0.08 & 283 & 35.46 & 2263 & 42.31 & & \\
\hline & & $\mathrm{a}$ & 0.76 & 0.03 & 0.79 & 0.07 & 0.68 & 0.05 & 303 & 21.38 & 2177 & 39.04 & & \\
\hline & & $\mathrm{u}$ & 0.77 & 0.02 & 0.80 & 0.03 & 0.79 & 0.01 & 260 & 20.00 & 2134 & 49.95 & 2620 & \\
\hline & Final & e & 0.75 & 0.05 & 0.76 & 0.10 & 0.57 & 0.05 & 297 & 21.38 & 2206 & 35.99 & & \\
\hline & & $\mathrm{a}$ & 0.63 & 0.04 & 0.61 & 0.03 & 0.49 & 0.06 & 374 & 70.91 & 2154 & 61.88 & & \\
\hline & & $\mathrm{u}$ & 0.70 & 0.03 & 0.64 & 0.02 & 0.65 & 0.02 & 283 & 26.90 & 2146 & 56.23 & 2610 & 98.99 \\
\hline & Interv & $\underline{\text { a }} 9$ & 0.24 & 0.04 & 0.22 & 0.04 & 0.19 & 0.02 & 591 & 26.22 & 1910 & 13.35 & 2545 & 63.62 \\
\hline & & $\underline{99}$ & 0.36 & 0.05 & 0.28 & 0.03 & 0.37 & 0.08 & 455 & 19.01 & 1734 & 11.77 & 2589 & 158.00 \\
\hline & & u9 & 0.20 & 0.03 & 0.16 & 0.02 & 0.18 & 0.02 & 543 & 26.42 & 1744 & 93.65 & 2462 & 119.14 \\
\hline & & פ९ & 0.26 & 0.01 & 0.24 & 0.00 & 0.18 & 0.02 & 533 & 15.32 & 1841 & 43.95 & 2524 & 68.51 \\
\hline & & $9 \underline{a}$ & 0.22 & 0.02 & 0.20 & 0.03 & 0.18 & 0.00 & 687 & 28.90 & 1709 & 44.92 & 2301 & 57.99 \\
\hline & & ua & 0.21 & 0.04 & 0.16 & 0.06 & 0.18 & 0.02 & 653 & 61.50 & 1688 & 46.30 & 2295 & 77.23 \\
\hline
\end{tabular}

\begin{tabular}{|c|c|c|c|c|c|c|c|c|c|c|c|c|c|c|}
\hline \multirow{12}{*}{$\begin{array}{c}\text { Means } \\
\text { across } \\
\text { speakers }\end{array}$} & \multirow[t]{3}{*}{ Initial } & e & 0.66 & 0.11 & 0.65 & 0.15 & 0.73 & 0.08 & 286 & 31.41 & 2340 & 115.44 & 3190 & \\
\hline & & $\mathrm{a}$ & 0.67 & 0.12 & 0.66 & 0.15 & 0.72 & 0.08 & 316 & 20.48 & 2283 & 146.29 & 3191 & \\
\hline & & $\mathrm{u}$ & 0.70 & 0.13 & 0.72 & 0.14 & 0.79 & 0.07 & 277 & 23.13 & 2268 & 135.35 & 2663 & 84.51 \\
\hline & \multirow[t]{3}{*}{ Final } & e & 0.64 & 0.10 & 0.63 & 0.15 & 0.63 & 0.08 & 318 & 16.72 & 2296 & 154.35 & 2810 & 74.75 \\
\hline & & $\mathrm{a}$ & 0.60 & 0.06 & 0.56 & 0.07 & 0.61 & 0.07 & 346 & 25.02 & 2272 & 134.50 & 2844 & 264.66 \\
\hline & & $\mathrm{u}$ & 0.62 & 0.10 & 0.57 & 0.11 & 0.67 & 0.05 & 311 & 23.88 & 2250 & 190.79 & 2720 & 139.11 \\
\hline & \multirow[t]{6}{*}{ Interv } & $\underline{\text { ạ }}$ & 0.19 & 0.05 & 0.13 & 0.07 & 0.21 & 0.06 & 546 & 32.55 & 1936 & 117.26 & 2643 & 141.09 \\
\hline & & $\underline{99}$ & 0.31 & 0.07 & 0.21 & 0.09 & 0.34 & 0.05 & 452 & 36.60 & 1900 & 200.24 & 2613 & 110.04 \\
\hline & & 노 & 0.26 & 0.09 & 0.18 & 0.09 & 0.26 & 0.07 & 456 & 69.56 & 1829 & 181.99 & 2505 & 128.37 \\
\hline & & $\underline{99}$ & 0.26 & 0.08 & 0.18 & 0.09 & 0.27 & 0.08 & 498 & 42.74 & 1903 & 169.99 & 2608 & 120.06 \\
\hline & & $9 \underline{a}$ & 0.25 & 0.05 & 0.17 & 0.07 & 0.28 & 0.07 & 589 & 68.03 & 1846 & 174.59 & 2567 & 163.29 \\
\hline & & ua & 0.26 & 0.09 & 0.19 & 0.09 & 0.24 & 0.08 & 570 & 63.72 & 1792 & 247.97 & 2432 & 84.82 \\
\hline
\end{tabular}




\section{Vowel context}

\subsection{Initial and final positions}

According to results from ANOVA2 tests, all contact indices showed significantly higher values in initial vs. final position, and a significant effect of vowel context $(\mathrm{Qp}=\mathrm{F}(2,58)=5.14, \mathrm{p}<0.01 ; \mathrm{CA}=\mathrm{F}(2,58)=26.60, \mathrm{p}<0.001$; $\mathrm{CCp}=\mathrm{F}(2,58)=3.35, \mathrm{p}<0.05)$. Bonferroni multiple comparisons revealed the existence of significantly higher values for $[j]$ in the context of $[u]$ than in the context of [a] (Qp, CCp) and [e, a] (CA) (see mean data across speakers in Table II). There was also a significant position $\mathrm{x}$ vowel interaction for $\mathrm{Qp}$ and $\operatorname{CCp}(\mathrm{F}(2,58)=9.43, \mathrm{p}<0.001 ; \mathrm{F}(2,58)=10.74, \mathrm{p}<0.001)$ which was associated with the difference $[\mathrm{u}]>[\mathrm{e}, \mathrm{a}]$ in word initial position but not word finally where dorsopalatal contact turned out to decrease in the progression $[\mathrm{e}]>[\mathrm{a}$, $\mathrm{u}$. Thus, low [a] causes initial and final [j] to undergo a decrease in dorsopalatal contact while maximal dorsopalatal contact may occur in the context of $[\mathrm{u}]$ or $[\mathrm{e}]$ depending on the word position taken into consideration.

The acoustic data yielded significantly higher $\mathrm{F} 1$ values word finally than word initially and significantly higher F2 values word initially than word finally. There was a significant main effect of vowel context for both formants $(\mathrm{F} 1=\mathrm{F}(2,58)=28.95, \mathrm{p}<0.001 ; \mathrm{F} 2=\mathrm{F}(2,58)=14.15, \mathrm{p}<0.001)$ but no significant position $x$ vowel interaction. Vocalic effects occurred for $[\mathrm{a}]>[\mathrm{e}$, $\mathrm{u}](\mathrm{F} 1)$ and for $[\mathrm{e}]>[\mathrm{a}, \mathrm{u}](\mathrm{F} 2)$ (see mean data across speakers in Table II). To summarize, low [a] causes [j] to have a higher F1 than higher vowels and a lower F2 than front vowels.

\subsection{Intervocalic position}

ANOVA3 tests yielded a highly significant effect of vowel context for all contact indices and acoustic parameters, i.e., $\mathrm{Qp}(\mathrm{F}(5,100)=18.56, \mathrm{p}<0.001)$, CA $\quad(\mathrm{F}(5,100)=17.91, \quad \mathrm{p}<0.001), \quad \mathrm{CCp} \quad(\mathrm{F}(5,100)=10.02, \quad \mathrm{p}<0.001), \quad \mathrm{F} 1$ $(\mathrm{F}(1,20)=72.07, \mathrm{p}<0.001)$ and $\mathrm{F} 2(\mathrm{~F}(1,20)=18.33, \mathrm{p}<0.001)$. (A correction of the degrees of freedom, i.e., 1, 20 rather than 5,100, was applied to the ANOVAs for the F1 and F2 data since the sphericity condition could not always be met). There was also a significant effect of 'speaker' which will be reported and discussed in section 4.

Table III presents Qp, CCp, CA, F1 and F2 significant differences for all vowel context pairs according to Bonferroni multiple comparisons (see also mean values across speakers in Table II). The rightmost column in the table reveals the number of times that a given vocalic sequence in a specific row shows higher contact index or formant frequency values than all other sequences. Thus, a Qp value of 0 for the sequence ['aə] means that [j] is produced with less dorsopalatal contact in this contextual environment than in all other five sequences; on the other hand, a Qp value of 5 for ['əə] indicates that the palatal glide exhibits more contact at the palatal zone in this sequence than in the remaining sequences. 
TABLE III. Significant Qp, CCp, CA, F1 and F2 differences for intervocalic [j] as a function of vowel context according to Bonferroni multiple comparisons tests. Stressed vowels in the VCV sequences appear underlined. Angles indicate that the vocalic sequences in the rows exhibit a higher ( $>$ ) or a lower $(<)$ value than the vocalic sequences in the columns. Asterisks correspond to the significance levels $0.05\left(^{*}\right), 0.01\left(^{* *}\right), 0.001\left(^{* * *}\right)$. The rightmost column reports the number of times that a vowel sequence at a given row presents higher values than all other sequences under analysis.

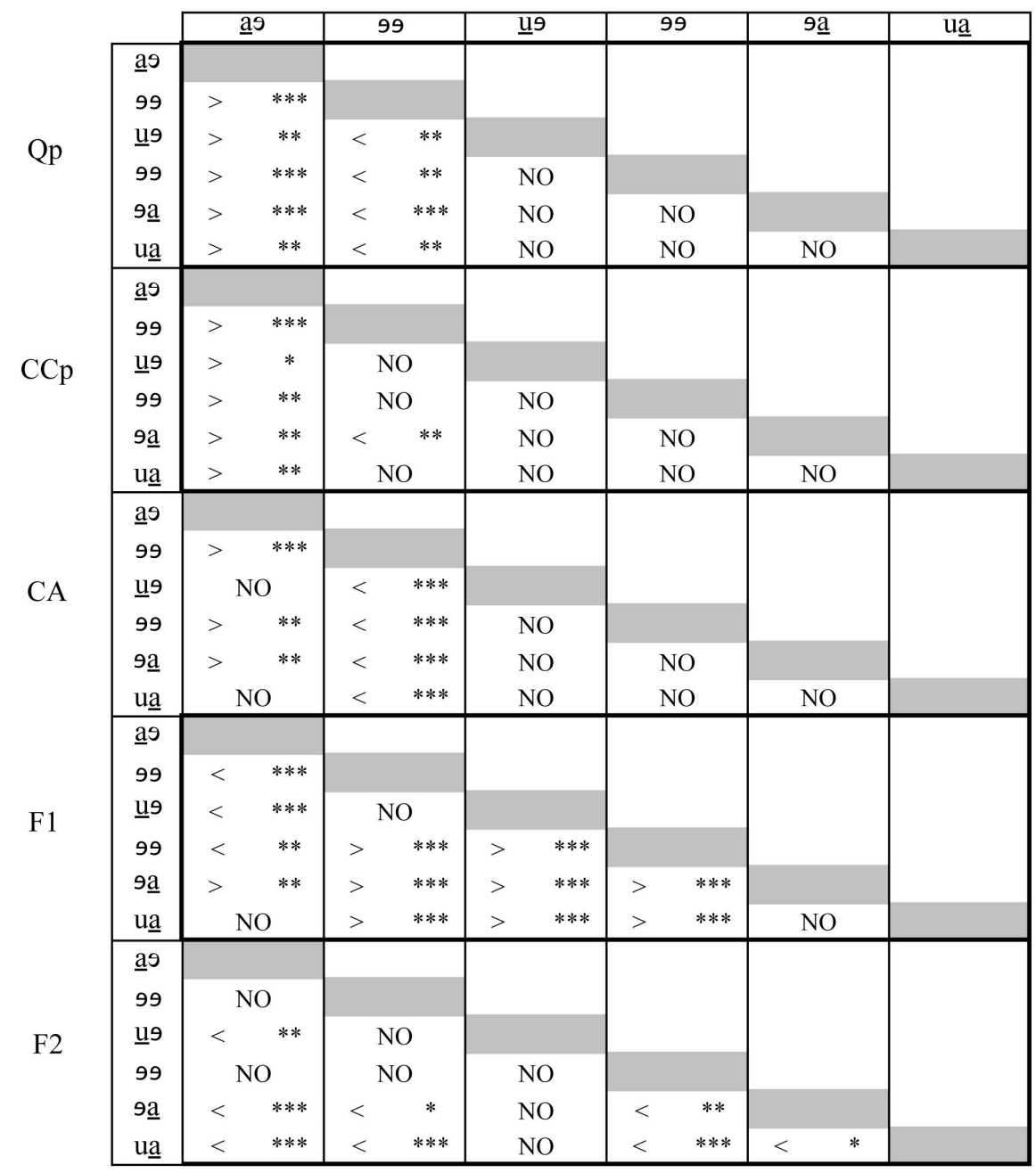


According to the statistical results presented in the table, contextual [a] causes [j] to achieve a maximal F1 frequency; thus, as shown in the rightmost column, F1 values for sequences with [a], i.e., ['aə, ə'a, u'a], are consistently higher than those for the other sequences. On the other hand, [j] exhibits the lowest F2 value when occurring next to [u], i.e., a value of 0 for ['uə] and [u'a] means that $\mathrm{F} 2$ for [j] is lower in those two sequences than in all other sequences under analysis. Results for the contact index Qp are only in partial agreement with those for F1. Thus, the F1 rising effect of [a] is not matched by a decrease in dorsopalatal contact size, e.g., [ə'a] and [u'a] exhibit a maximal F1 frequency but not less dorsopalatal contact than sequences without [a]. This lack of correspondence between F1 and Qp suggests that prominent acoustic differences between contextual realizations of intervocalic [j] may be associated with differences in oral opening rather than with differences in tongue dorsum raising. There is a better match between F2 and $\mathrm{CA}$ since sequences with [u], i.e., ['uə] and [u'a], show the lowest F2 and a minimal contact fronting degree.

The statistical results reported in Table III also reveal an increase in F1 frequency and a decrease in dorsopalatal contact as a function of stressed [a] when this vowel follows rather than precedes the palatal glide, i.e., [ə'a] > ['aə] for F1, Qp and CCp. Moreover, the glide also exhibits a higher F1 when followed by stressed [a] than by unstressed [ə], i.e., [u'a] > ['uə]. It may be thus concluded that [j] lowering is specially prone to occur before stressed [a].

\section{F3}

According to Figure 2 and Table II, F3 exhibits similar position-dependent differences to the other articulatory and acoustic parameters in the context of non-back labial vowels, i.e., higher values for initial [j] $(3190 \mathrm{~Hz}$ for [je, ja]) than for final [j] $(2844 \mathrm{~Hz}$ for [aj], $2810 \mathrm{~Hz}$ for [ej]). F3 frequencies are specially low in the context of [u] $(2663 \mathrm{~Hz}$ for [ju], $2720 \mathrm{~Hz}$ for [uj]), probably since the front cavity lengthens considerably as the lips round and protrude. Moreover, sequences with intervocalic [j] show a lower F3 (betwen $2430 \mathrm{~Hz}$ and $2645 \mathrm{~Hz}$ ) than sequences with initial and final [j] (above $2650 \mathrm{~Hz}$ ).

\section{A comparison with vowel acoustics and articulation}

\subsection{Across speakers}

Figure 3 presents mean F1 x F2 values for all sequences under study across speakers and repetitions. Formant values for the $[\mathrm{j} V, \mathrm{Vj}]$ sequences are indicated by filled circles while those for the $[\mathrm{VjV}]$ sequences are identified with crosses and the corresponding phonetic transcription with stress vowels underlined. F1 x F2 values for the Majorcan vowels [i, e, $\varepsilon, a, 0, o, u]$ averaged across several consonantal contexts and the same Majorcan Catalan speakers (Recasens and Espinosa, submitted (b)) are also plotted for comparison with the formant values of the palatal glide. 
FIGURE 3. F1 x F2 values for initial and final [j] (filled circles), intervocalic [j] (crosses), and the vowels [i, e, $\varepsilon, a, 0, o, u]$ averaged across the five Majorcan Catalan speakers AR, BM, MJ, ND and CA. The flanking vowels of the $[\mathrm{VjV}]$ sequences are given in phonetic transcription with the stressed vowels underlined.

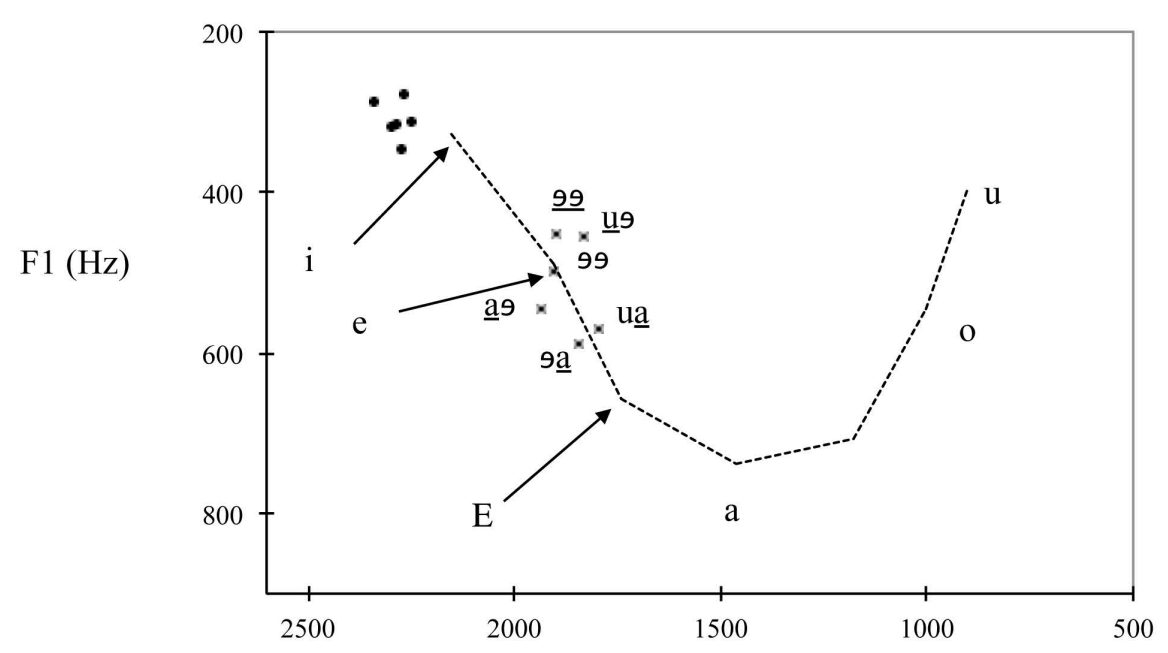

$\mathrm{F} 2(\mathrm{~Hz})$ 
FIGURE 4. Qp (top) and F1 (bottom) values for intervocalic [j] in the vowel sequences ['aə, 'əə, 'uə, əə, ə'a, u'a] and for the vowels [i, e, $\varepsilon, \mathrm{a}]$ according to the Majorcan Catalan speakers AR, BM, MJ, ND and CA. Stressed vowels appear underlined in the vowel sequences of interest.

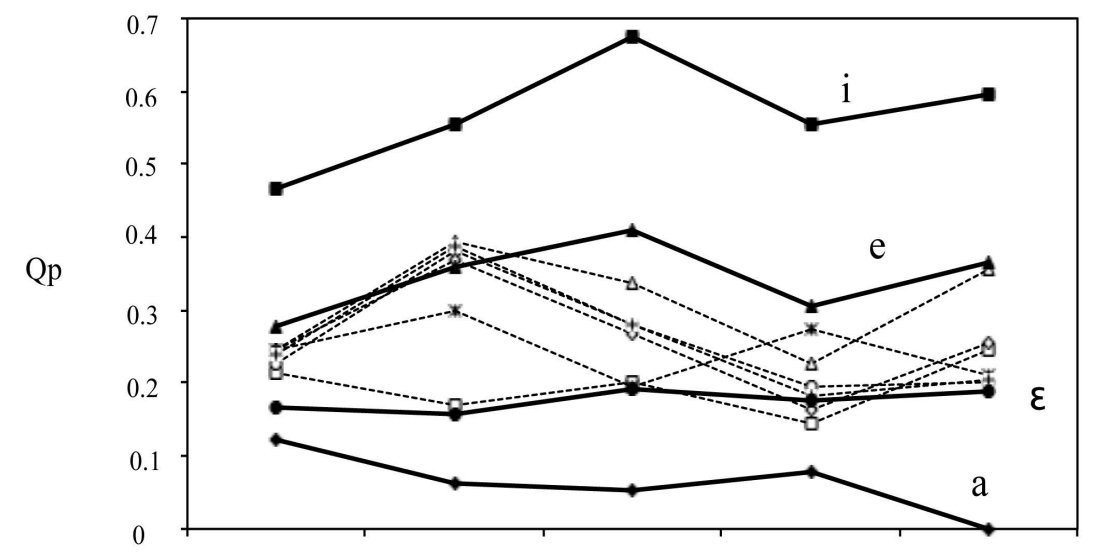

\begin{tabular}{|c|c|}
\hline$\square$ & $\underline{\mathrm{a}} 9$ \\
\hline$\Delta$ & $\underline{9}$ \\
\hline 0 & $\underline{\mathrm{u}} \mathrm{S}$ \\
\hline$\diamond$ & $\overline{9}$ \\
\hline * & 9 \\
\hline+ & \\
\hline
\end{tabular}

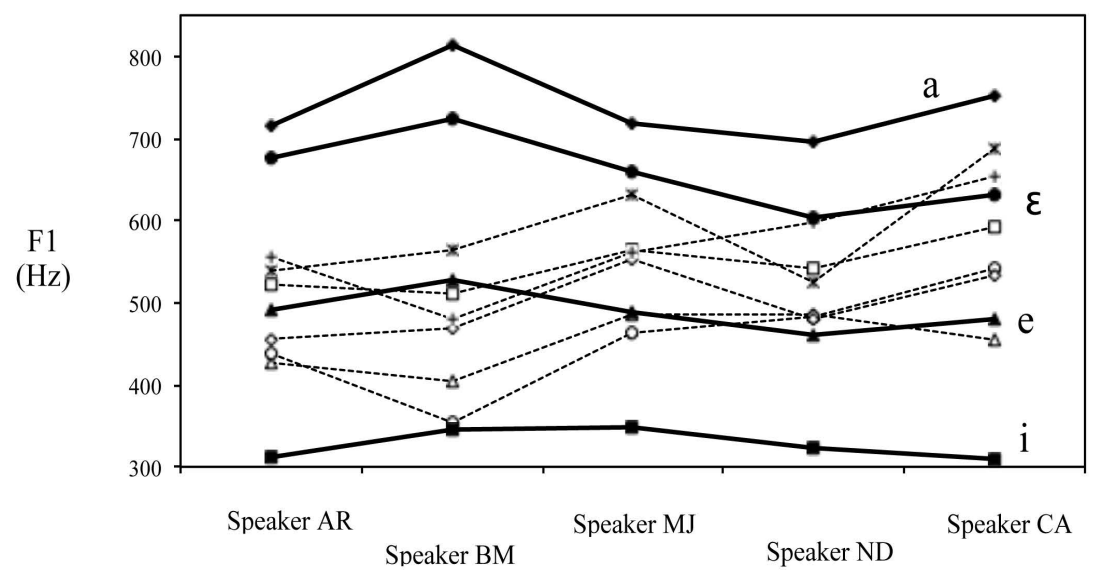


According to the figure, the initial and final allophones of [j] occupy roughly the same acoustic position as [i] and exhibit even more extreme formant frequency values i.e., a lower F1 and a higher F2, than those for the high front vowel. Regarding intervocalic [j], F1 for the consonant in vowel sequences without contextual [a] (i.e., ['uə, 'əə, əə]) lies close to F1 for the vowel [e], and F1 for [j] in the context of [a] (i.e., ['aə, u'a, ə'a]) approaches $\mathrm{F} 1$ for $[\varepsilon]$. Moreover, intervocalic [j] appears to be most centralized in the context of $[\mathrm{u}]$ independently of whether $\mathrm{F} 1$ is lower (['uə]) or higher ([u'a]).

The degree of dorsopalatal contact for intervocalic $[\mathrm{j}]$ is related to that for vowels in a similar fashion to F1 and F2. Thus, according to Table II, Qp values across speakers occur between 0.66 and 0.70 for initial [j] and between 0.60 and 0.64 for final [j], while Qp values for intervocalic [j] range between 0.2 and 0.3 (0.31 ['əə], 0.26 ['uə, u'a, əə], 0.25 [ə'a], 0.19 ['aə]). On the other hand, Qp for Majorcan front and low vowels according to the same speakers amounts to 0.57 ([i]), 0.34 ([e]), 0.18 ([ع]) and 0.08 ([a]) (Recasens and Espinosa, submitted (b)). A comparison between the two sets of values allow concluding that initial and final [j] are articulated with more dorsopalatal contact than [i], while the degree of palatal contact for intervocalic [j] is intermediate between that for $[\mathrm{e}]$ and that for $[\varepsilon]$.

\subsection{Individual speakers}

A more detailed insight into the phonetic relationship between intervocalic $[\mathrm{j}]$ and vowels in Majorcan Catalan may be gained through an analysis of the linguopalatal contact and formant frequency values for the individual speakers. Figure 4 shows data for Qp (upper graph) and F1 (lower graph) for [j] in the six intervocalic sequences ['aə, 'əə, 'uə, əə, ə'a, u'a] according to speakers AR, BM, MJ, ND and CA (dotted lines); graphs also report Qp and $\mathrm{F} 1$ values for the four vowels $[i, \mathrm{e}, \varepsilon, \mathrm{a}]$ for the same speakers (thick continuous lines). According to the F1 data in the bottom graph, intervocalic [j] is implemented through different speaker-dependent vocalic qualities: close to [e] (speaker AR); between [i] and [e] (speaker BM); between [e] and

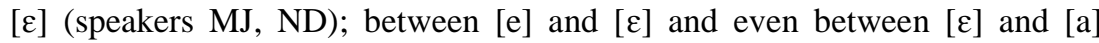
(speaker CA). Qp values for intervocalic [j] in the upper graph of the figure lie between those for $[\mathrm{e}]$ and $[\varepsilon]$ for the most part.

An interesting aspect about the data plotted in the bottom graph of Figure 4 is that all speakers show highly similar contextual differences in F1 frequency, i.e., F1 for [j] often reaches its maximum for [ə'a] and its minimum for ['əə] and ['uə] while values for the remaining sequences [u'a], ['aə] and [əə] fall somewhere in between. Therefore, we are not facing a random F1 distribution but relatively well defined (higher or lower) phonetic realizations of [j] varying as a function of factors such as vowel context and stress. According to the Qp data for speaker ND (see top graph), the sequence eia in the word roveiat exhibits maximal dorsopalatal contact presumably in line with the fact that it was uttered as [e'ja] rather than as [ə'ja]. 
FIGURE 5. F1 x F2 values for initial and final [j] (filled circles), intervocalic [j] (crosses) and the vowels [i, e, $\varepsilon, a, \rho, o, u]$ for each of the Majorcan speakers AR, BM, MJ, ND and CA. The flanking vowels of the [VjV] sequences are given in phonetic transcription with the stressed vowels underlined.

$\mathrm{F} 1(\mathrm{~Hz})$
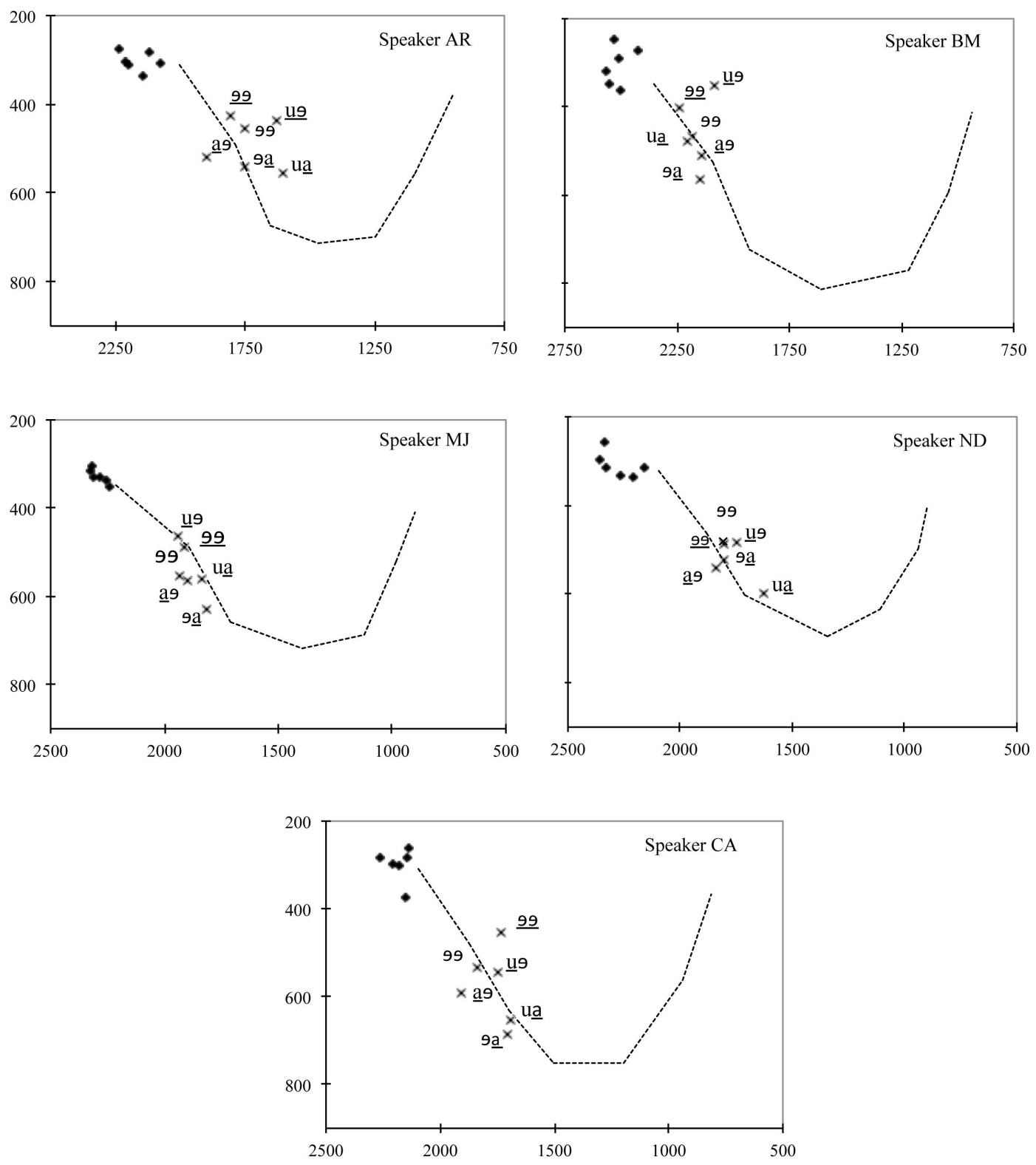

F2 (Hz) 
Speaker-dependent differences in the acoustic relationship between [j] and the seven vowels of Majorcan Catalan may be investigated through inspection of the F1 x F2 plots in Figure 5. These graphic displays show speaker-dependent values for $[\mathrm{VjV}]$ sequences (crosses), $[\mathrm{jV}, \mathrm{Vj}]$ sequences (filled circles) and the vowels [i, e, $\varepsilon, a, o, o, u]$ (occurring at the same location as in the F1 x F2 plot of Figure 3). According to the formant values for speaker $\mathrm{BM},[\mathrm{j}]$ occupies a position between [i] and [e], and sequences with a contextual low vowel exhibit a higher F1 than those without it; maximum centralization affects the sequence with the lowest F1 (i.e., ['uə]). Speaker AR shows a glide realization close to that for the vowel [e]; moreover, sequences with [a] are lower than those without [a], and F1 x F2 values for sequences with $[\mathrm{u}]$ may be quite centralized. Values for speakers MJ and ND encompass those for $[e]$ and $[\varepsilon]$ such that the presence of contextual [a] causes [j] to be $[\varepsilon]$-like and its absence accounts for an [e]-like realization of the palatal glide. Finally, the [j] realizations for speaker CA are generally lower than those for the other four speakers, and their formant frequencies occur between those for [e] and $[\varepsilon]$ and even between those for $[\varepsilon]$ and [a] when the vocalic sequence includes a low vowel; moreover, phonetic realizations with a low F1 (['uə, 'əə]) are specially centralized.

In the light of these speaker-dependent differences, it may be hypothesized that a sound change is under way in present-day Majorcan Catalan. The finding that speaker CA exhibits lower realizations of intervocalic $[j]$ than the remaining Majorcan speakers is consistent with the possibility that he is linguistically more conservative than them. Additional data reveal that this speaker preserves several recessive phonetic characteristics of Majorcan Catalan speech (see Introduction). Thus, he keeps the underlying voicing distinction in word final stop clusters with a liquid, e.g., /bl/ vs. /pl/ (assembl "I resemble", acopl "I fit together"), /br/ vs. /pr/ (sembr "I sow", compr "I buy"); spectrographic data reveal indeed that, differently from speakers AR, $\mathrm{BM}$ and $\mathrm{MJ}$ and to some extent speaker ND, speaker CA shows vocal fold vibration during the stop in voiced stop clusters with $/ \mathrm{r} /$ and during the stop and the liquid in voiced stop clusters with /1/ (Recasens and Espinosa, 2004). Moreover, his palatal stop allophone of $/ \mathrm{k} /$ exhibits a full laminodorsal closure all over the alveolar and palatal zones while central closure for the other speakers takes place at the palatal zone or at the postalveolo-prepalatal zone only (Recasens and Espinosa, in press (a)). In comparison to the other four Majorcan Catalan speakers, speaker CA also has more extreme (mid) low vowel productions, namely, a lower realization of $/ \mathrm{s} /$, a higher and more anterior realization of $/ \mathrm{a} /$, and a lower and more retracted realization of stressed /ə/ (Recasens and Espinosa, in press (b)).

It may also be suggested that low realizations of intervocalic [j] such as those exhibited by speaker CA were prevalent at a former historical stage when the palatal approximant was sufficiently low to undergo elision, as in 
fact happened in Minorcan Catalan and in several geographical areas of Majorcan Catalan (see Introduction). Higher realizations of intervocalic [j] may be viewed as more modern, less stigmatized phonetic variants through which less conservative speakers seek to preserve the segmental integrity of the consonant.

\subsection{Variability}

Standard deviations for intervocalic [j] across sequence means and speakers amount to 3.8 for Qp, 58.6 for F1 and 54.1 for F2. In the light of vowel data for the same Majorcan Catalan speakers (Recasens and Espinosa, in press (b)), the F1 standard deviation value for intervocalic [j] (58.6) is clearly higher than the F1 deviations across consonantal contexts for the three front vowels [i] (28.8), [e] (35.1) and [ $\varepsilon]$ (24.3). This finding indicates that the intervocalic palatal glide is highly variable and unspecified for a well defined articulatory target along the vowel height dimension. Contextual variability values for intervocalic [j] are similar to those for [i, e, $\varepsilon$ ] in the case of Qp (about 3.7-3.9), and analogous or lower to those for [i, e, $\varepsilon$ ] in the case of F2 (71.7, 106.9, 57.1).

The five upper panels of Table II provide data on dorsopalatal contact and formant frequency variability across repetitions of each vocalic sequence for each speaker. Token-to-token variability reflects the degree of precision used by speakers for the achievement of the articulatory target for a given consonant in specific contextual and positional conditions. If we concentrate on F1 variability (and thus on variability associated with tongue dorsum height and oral opening), standard deviation values for the individual speakers in the table reveal a trend for intervocalic [j] to be more variable in sequences with contextual [a] than in those without this contextual vowel. In our study of Catalan vowels, [a] was also been reported to exhibit a higher degree of token-to-token F1 variability than other stressed vowels.

\section{Articulatory-acoustic correlations}

Articulatory-acoustic correlations yielded high $\underline{\mathrm{r}}$ values when performed on sequence averages across positions. Correlation values were high and negative in the case of the Qp-F1 pair (-0.87) and high and positive for Qp-F2 (0.81), and could exceed 0.9 when carried out on data for the individual speakers $(\mathrm{Qp}-\mathrm{F} 1=-0.95, \mathrm{Qp}-\mathrm{F} 2=0.94) . \mathrm{Qp}-\mathrm{F} 1$ and Qp-F2 correlations yielded low $\underline{\mathrm{r}}$ values however when performed on data for each position, and higher $\underline{r}$ values for the intervocalic condition $(\mathrm{Qp}-\mathrm{F} 1=-0.51, \mathrm{Qp}-\mathrm{F} 2=0.59)$ than for the initial and final conditions (below 0.3).

These statistical results indicate that both formant frequencies are closely related to dorsopalatal contact size but only so when a considerable range of degrees of tongue dorsum contact is taken into consideration. In other words, high articulatory-acoustic correlation values are associated with the contrast 
between the linguopalatal contact and formant frequency values for initial and final $[j]$, on the one hand, and for intervocalic [j], on the other hand. Therefore, it appears that a substantial decrease in Qp as we proceed from initial and final [j] to intervocalic [j] causes F1 to increase and F2 to decrease considerably.

This finding is in agreement with rates of F2 variation during the formation of a prototypical [j] realization (Recasens, Fontdevila and Pallarès, 1995). Thus, data for Eastern Catalan show a large increase in F2 and F3 frequency as the dorsopalatal constriction is being narrowed during the initial stage of [j] (i.e., from $1500 \mathrm{~Hz}$ to $2000 \mathrm{~Hz}$ for F2 and from $2500 \mathrm{~Hz}$ to 3000 $\mathrm{Hz}$ for $\mathrm{F} 3$ ), and a smaller $\mathrm{F} 2$ rise by about $50-130 \mathrm{~Hz}$ after the articulatory configuration of [j] has essentially been achieved. Dorsopalatal contact and formant frequency changes during the former phase parallel those occurring as we proceed from intervocalic [j] to initial or final [j] in Majorcan Catalan.

F1-F2 correlations seeking to investigate whether [j] centralization and lowering were related or not yielded similar results to the Qp-F1 and Qp-F2 correlations. Thus, $\underline{\mathrm{r}}$ values for F1-F2 correlation analyses performed on all sequence means turned out to be high and negative, i.e., -0.78 (all speakers) and up to -0.95 (individual speakers). However, F1-F2 correlations carried out on data for each word position independently were generally low, i.e., below -0.4 (all speakers) and -0.52 (individual speakers). In summary, only when data for all sequences are taken into account, an increase in F1 frequency for intervocalic [j] vs. initial and final [j] cooccurs with a decrease in F2.

\section{Trajectories}

Figure 6 presents mean F1 and F2 trajectories across repetitions for all six $[\mathrm{VjV}]$ sequences according to each Majorcan Catalan speaker. As pointed out in the Introduction, these trajectories provide indirect information about tongue body position and degree of palatal constriction, i.e., the higher F2, the higher the degree of dorsopalatal constriction for the consonant. Moreover, the achievement of a high F2 for [j] may mean that the consonant has reached its appropriate articulatory target.

For four speakers (AR, BM, MJ, ND), the fact that $\mathrm{F} 2$ rises from V1 until [j] and may lower from [j] until V2 is in agreement with the hypothesis that the palatal glide is actively controlled. In this case, the VC rising movement is generally larger than the subsequent $\mathrm{CV}$ lowering movement since $\mathrm{V} 1$ is preceded by a labial consonant exhibiting a low F2 locus about $1000 \mathrm{~Hz}$. On the other hand, there is often a small F2 frequency distance between [j] and following [ə] or stressed [a] which may render the palatal glide and the following vowel indistinguishable. The realization [rove'at] of the word roveiat for speaker ND is in accordance with little F2 rising from $\mathrm{V} 1=[\mathrm{e}]$ towards [j] in this case (see thick F1 and F2 traces in the right middle graph). 
FIGURE 6. Mean F1 and F2 trajectories across repetitions of the six [VjV] sequences under analysis for each of the Majorcan speakers AR, BM, MJ, ND and CA. Formant trajectories have been lined up at the F2 frequency maximum. The thick trace in the right middle graph corresponds to the sequence [ $\left.\mathrm{e}^{\prime} \mathrm{j} \mathrm{j}\right]$ of the word roveiat according to speaker ND.
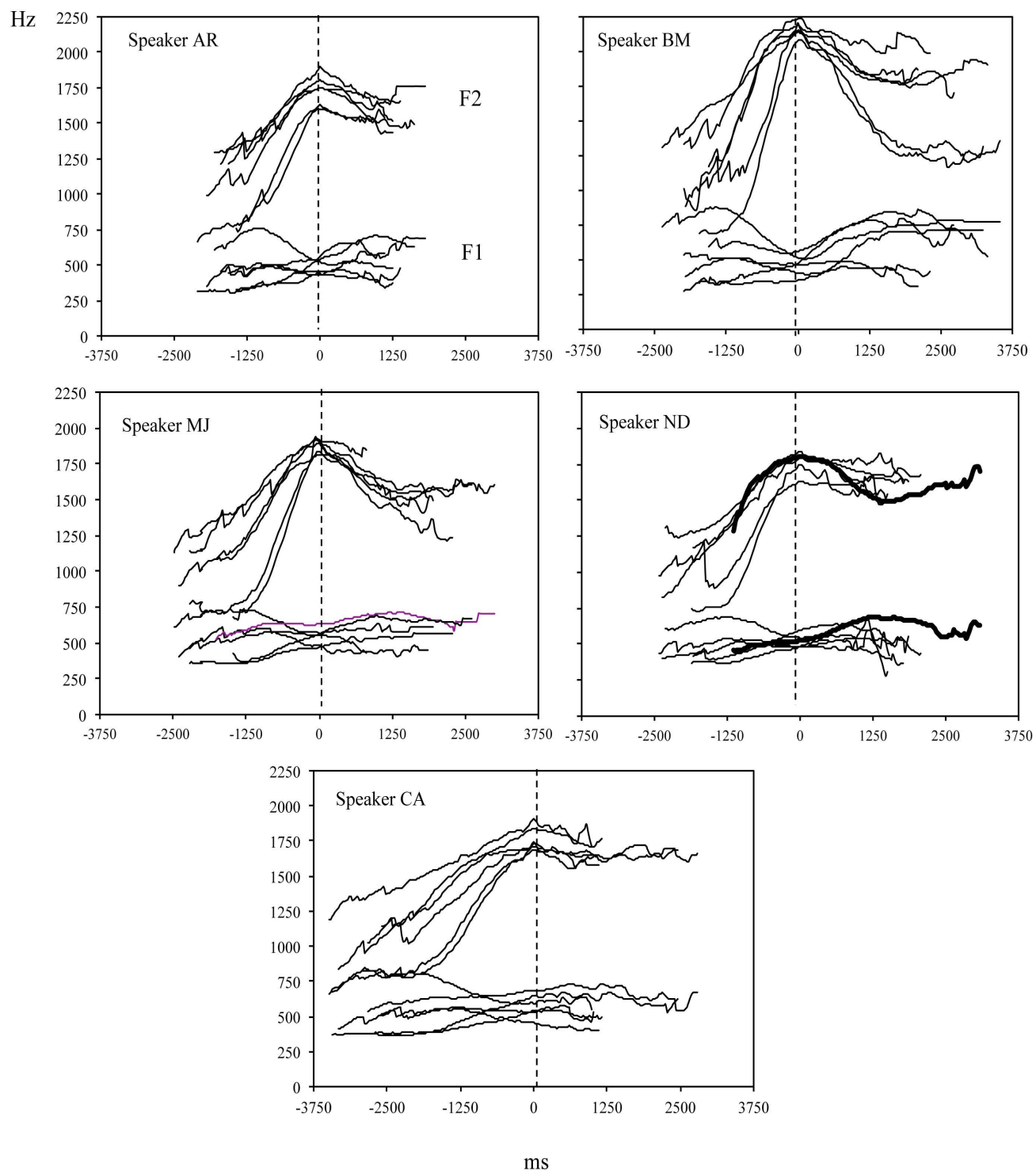
Regarding $[\mathrm{VjV}]$ sequences for speaker $\mathrm{CA}$ (low graph), the palatal approximant exerts prominent and long-lasting carryover effects onto $\mathrm{V} 2=[\partial$, a]. Indeed, F2 trajectories for this speaker exhibit relatively slow rising VC transitions, a late achievement of the [j] target, and a short and flat $\mathrm{CV}$ portion.

For practically all speakers, the presence of $\mathrm{V} 1=[\mathrm{u}]$ in the sequences ['uja, $\mathrm{u}^{\prime} \mathrm{ja}$ ] causes the VC rising transition to proceed late and fast, and $\mathrm{F} 2$ at $[\mathrm{j}]$ midpoint to be lower than expected. This delay in the F2 rising motion may be attributed to the fact that the tongue dorsum must travel a long distance from a retracted position for back labial $[\mathrm{u}]$ to a more anterior position for the palatal glide. F2 rising also occurs later and more rapidly for [ə'ja] and ['əjə] than for ['ajə] and [əjə] in the case of speakers BM and MJ and, to some extent, of speaker CA. Timing differences between [ə'ja] and ['ajə] suggest that anticipatory tongue dorsum lowering and backing effects associated with stressed $\mathrm{V} 2=[\mathrm{a}]$ contribute to a delay of the F2 rising movement during the $\mathrm{VC}$ portion of the $[\mathrm{VjV}]$ sequence.

It may be concluded that, while Majorcan Catalan speakers intend to produce an independent $[\mathrm{j}]$ gesture in $[\mathrm{VjV}]$ sequences, listeners may fail to distinguish the glide from the following vowel due to the acoustic affinity between the two consecutive phonetic segments. Acoustic similarity could be attributed to intrinsic low F2 and high F1 frequency values for lenited realizations of [j], but also to salient carryover coarticulatory effects exerted by the palatal glide on following [ə] or palatalized [a] and to prominent anticipatory effects exerted by stressed [a] on the preceding phonetic material.

\section{Discussion}

Analogously to other Catalan dialects, Majorcan Catalan [j] was found to exhibit a higher realization than [i] when occurring in word initial vs. word final position. This difference is consistent with a robust trend for initial consonants to strengthen through an increase in constriction degree and perhaps for their final cognates to weaken (Recasens, 2004).

$[\mathrm{VjV}]$ formant trajectories suggest that Majorcan Catalan speakers implement intervocalic [j] through an actively controlled articulatory configuration. Data show that this consonant is not realized invariably as [e] but as a mid vowel varying in tongue dorsum height and, probably more so, in oral opening degree, depending on vowel context and speaker. Moreover, there is no systematic relationship between [j] height and centralization. Conservative speakers (e.g., speaker CA) exhibit specially low variants of the intervocalic palatal glide which may have been frequent at the time that the consonant underwent elision in Minorcan Catalan and several Majorcan places. This hypothesis is in accordance with contextual data showing that those low variants are favored by the presence of adjacent [a], mostly if stressed and occurring after $[\mathrm{j}]$; contextual $[\mathrm{u}]$ favors higher and more 
retracted consonant realizations while [ə] does not seem to affect the phonetic characteristics of the consonant substantially.

Following Labov (1994) and in agreement with other lenition processes, it may be hypothesized that the Majorcan Catalan palatal glide was heavily lenited in favorable (mid) low vowel environments in the past. The fact that $/ \varepsilon, \mathrm{o} /$ are specially low and /a/ is specially close and front in this Catalan dialect may have favored this phonetic implementation. The glide must have also been highly variable along the height dimension and prone to be confused with any adjacent vowel. Therefore, elision may have occurred in different contextual conditions and thus, affected higher glide realizations in higher vowel contexts and lower glide variants in lower vowel contexts. The process in question may have been caused by the failure to distinguish [j] from following vowels such as [o, a] which have been shown to be heavily coarticulated with the palatal glide in $[\mathrm{VjV}]$ sequences. In other languages and in Majorcan areas where intervocalic [j] elision does not apply systematically, the glide is not strongly reduced and may drop through gestural overlap in $[\mathrm{VjV}]$ sequences with (mid) high front vowels only. Also in American Spanish dialects, intervocalic [j] is prone to be absorbed by a wide variety of contextual vowels if strongly lenited or only by (mid) high front vowels if moderately lenited depending on the geographical area and perhaps the group of speakers involved.

The present sociolinguistic scenario appears to differ considerably with respect to that in the past. Indeed, most Majorcan Catalan speakers analyzed in the present study appear to lead a sound change through which intervocalic [j] has ceased to exhibit low realizations. These middle-class speakers are probably getting rid of this and other archaic markers of regional status by approaching their speech to Spanish or to the prestigious Barcelona variety of Catalan.

This study provides relevant data on the structure of consonant lenition and on those factors contributing to the deletion of lenited consonants in general. Regarding the former issue, intervocalic [j] realizations were found to depend heavily on vowel context such that all speakers turned out to exhibit similar F1 differences among contextual conditions. Moreover, these contextual realizations showed little random variability (except for those occurring next to [a], as expected). It may thus be concluded that, though sensitive to context, lenited consonants may be as stable as their non-lenited cognates. Regarding the second issue, the elision of intervocalic consonants appears to be ruled by the same principle as the elision of intervocalic [j], i.e., heavily coarticulated and highly variable realizations of $[\beta, \gamma]$ would be prone to be absorbed by spectrally similar back labial vowels but also to drop next to (mid) low vowels if extremely reduced. Listeners may fail to differentiate the consonant from the vowel in these circumstances and start out an elision process which may propagate throughout the lexicon.

Data reported in this paper suggest that more attention needs to be paid to the articulatory and acoustic characteristics of contextual segments in order to 
understand the phonetic factors causing consonant lenition and elision to occur. An instrumental evaluation of those phonetics characteristics should be carried out as a complement to phonetic transcription in sociolinguistic studies.

\section{Acknowledgements}

This research was funded by projects BFF2003-09453-C02-01 of the Ministry of Science and Technology of Spain and FEDER, and 2001SGR425 of the Generalitat de Catalunya. I would like to thank the comments by Hans van der Velde on a previous version of the manuscript.

\section{References}

Amastae, J. (1995) Variable spirantization: Constraint weighting in three dialects, Hispanic Linguistics, 6-7, 265-284.

Bibiloni, G. (1983) La llengua dels mallorquins. Anàlisi sociolingüística, $\mathrm{PhD}$ Dissetation, University of Barcelona.

Bladon, R. A. W. (1979) The production of laterals: Some acoustic properties and their physiological interpretation. In Current Issues in the Phonetic Sciences (Hollien, H. \& Hollien, P. editors), pp. 501-508, Amsterdam: John Benjamins.

Blasco, E. (1984) Storia lingüística della Sardegna. Tübingen: Niemeyer.

Browman, C.P. \& Goldstein, L. (1991) Gestural Structures: Distinctiveness, phonological processes, and historical change. In Modularity and the Motor Theory of Speech Production (Mattingly, I.G. \& Studdert-Kennedy, M., Hillsdale, editors), pp. 313-338. NJ: Lawrence Erlbaum Associates.

Browman, C.P. \& Goldstein, L. (1990) Tiers in articulatory phonology, with some implications for casual speech. In Papers in Laboratory Phonology I: Between the Grammar and Physics of Speech, (Kingston, J. \& Beckman, M.E., editors), pp. 341-376. Cambridge: Cambridge University Press.

Bouvier, J.-C. (1976) Les parlers provençaux de la Drôme. Paris: Klincksieck.

Cedergren, H. (1979) La elisión de la /d/: Un ensayo de comparación dialectal, Boletín de la Academia Puertorriqueña de la Lengua Española, 7(2), 19-29.

Cole, J., Hualde, J.I. \& Iskarous, K. (1998) Effects of prosodic and segmental context on /g/-lenition in Spanish. In Proceedings of LP'98, (Fujimura, O., Joseph, B.D. \& Palek, B., editors), 575-589. Prague: The Karolinum Press.

Contini, M. (1987) Étude de geographie phonétique et de phonétique instrumentale du sarde. Turin: Edizioni dell'Orso.

Espinosa, A. (1930) Estudios sobre el español de Nuevo Méjico, Biblioteca de Dialectología Hispanoamericana, 1, Buenos Aires.

Fant, G. (1960) Acoustic Theory of Speech Production. The Hague: Mouton.

Fontdevila, J., Pallarès, M.D. \& Recasens, D. (1994) The contact index method of EPG data reduction, Journal of Phonetics, 22, 141-154.

Frau, G. (1984) Friuli. Pisa: Pacini editore. 
Giannelli, L. \& Savoia, L. (1978-1980) L'indebolimento consonantico in Toscana, Rivista Italiana di Dialettologia, 2 (23-58), 3-4 (38-101).

Guarnerio, P.F. (1918) Fonologia Romanza. Milan: Urico Hoepli.

Haiman, J. \& Benincà, P. (1992) The Rhaeto-Romance Languages. London: Routledge.

Hardcastle, W.J., Jones, W., Knight, C., Trudgeon, A. \& Calder, G., (1989) New developments in electropalatography: a state-of the-art report, Clinical Linguistics and Phonetics, 3, 1-38.

Henríquez Ureña, P. (1938) El español de Méjico, los Estados Unidos y la América Central, Biblioteca de Dialectología Hispanoamericana, 4, Buenos Aires.

Jones, M. (1988) Sardinian. In The Romance Languages (Harris, M. \& Vincent, N., eds.), pp. 314-350. London and Sidney: Croom Helm.

Kirchner, R. (2004) Consonant lenition. In Phonetically based Phonology (Hayes, B., Kirchner, R. \& Steriade, D., eds.), pp. 313-345. Cambridge: Cambridge University Press.

Kohler, K.J. (1989) Segmental reduction in connected speech in German: Phonological facts and phonetic explanations. In Speech Production and Speech Modelling (Hardcastle, W.J. \& Marchal, A., eds.), pp. 69-92. Dordrecht, Boston and London: Kluwer.

Labov, W. (1994) Principles of Language Change, Volume 1: Internal Factors. Oxford and Cambridge, MA: Blackwell.

Lavoie, L. (2001) Consonant Strength. Phonological Patterns and Phonetic Manifestations. New York and London: Garland Publishing, Inc.

Lipski, J.M. (1994) El español de América. Madrid: Cátedra.

Lipski, J.M. (1990) Elision of Spanish intervocalic /y/: toward a theoretical account, Hispania, 73, 797-803.

López Morales, H. (1992) El español del Caribe. Madrid: Mapfre.

Mas, C. (1960) El habla del valle de Sóller. Masters Thesis, University of Barcelona.

Mascaró, J. \& Rafel, J. (1981) La $e$ intervocàlica baleàrica, Randa, 11, 37-44.

Mowrey, R. \& Pagliuca, W. (1985) The reductive character of articulatory evolution, Rivista di Linguistica, 7, 37-124.

Navarro Tomás, T. (1972) Manual de pronunciación española. Madrid: CSIC, $17^{\text {th }}$ edition.

Posner, R. (1997) Linguistic Change in French. Oxford: Clarendon Press.

Recasens, D. (2004) The effect of syllable position in consonant reduction. Articulatory and acoustic evidence from heterosyllabic consonant clusters, Journal of Phonetics, 32, 435-453.

Recasens, D. (1999) Lingual coarticulation. In Coarticulation (Hardcastle, W.J. \& Hewlett, N., eds.), pp. 80-104. Cambridge: Cambridge University Press.

Recasens, D. (1996) Fonètica descriptiva del català. Barcelona: Institut d'Estudis Catalans, $2^{\text {nd }}$ edition.

Recasens, D. (1986) Estudis de fonètica experimental del català oriental central. Barcelona: Publicacions de l'Abadia de Montserrat.

Recasens, D. \& Espinosa, A. (in press (a)) Articulatory, positional and contextual characteristics of palatal consonants. Evidence from Majorcan Catalan.

Recasens, D. \& Espinosa, A. (in press (b)) Dispersion and variability of Catalan vowels. 
Recasens, D. \& Espinosa, A. (2004) Underlying stop voicing in Majorcan Catalan word-final stop-liquid clusters, Phonetica, 95-118.

Recasens, D., Fontdevila, J. \& M.D. Pallarès (1995) Articulatory-acoustic correlations for tongue dorsum contact, Bulletin de la Communication Parlée, Institut de la Communication Parlée, Université de Grenoble, 3, 73-84.

Rohlfs, G. (1966) Grammatica storica della lingua italiana e dei suoi dialetti, Fonetica. Turin: Einaudi.

Stevens, K.N. (1998) Acoustic Phonetics. Cambridge: The MIT Press.

Terrell, T. (1979) Final /s/ in Cuban Spanish, Hispania, 62, 599-612.

Wells, J. C. (1982) Accents of English, 3 volumes. Cambridge: Cambridge University Press.

Zamora Vicente, A. (1989) Dialectología española. Madrid: Gredos, $2^{\text {nd }}$ edition.

\section{Daniel Recasens}

Laboratori de Fonètica

Institut d'Estudis Catalans and

Departament de Filologia Catalana

Universitat Autònoma de Barcelona

Bellaterra, Barcelona, Spain

daniel.recasens@uab.es
Aina Espinosa

Laboratori de Fonètica

Institut d'Estudis Catalans

aespinosa@iecat.net 